\title{
Recovery from heat, salt and osmotic stress in Physcomitrella patens requires a functional small heat shock protein PpHsp16.4
}

\author{
Cecilia Ruibal ${ }^{1}$, Alexandra Castro1, Valentina Carballo ${ }^{1,3}$, László Szabados² and Sabina Vidal ${ }^{*}$
}

\begin{abstract}
Background: Plant small heat shock proteins (sHsps) accumulate in response to various environmental stresses, including heat, drought, salt and oxidative stress. Numerous studies suggest a role for these proteins in stress tolerance by preventing stress-induced protein aggregation as well as by facilitating protein refolding by other chaperones. However, in vivo evidence for the involvement of sHsps in tolerance to different stress factors is still missing, mainly due to the lack of appropriate mutants in specific sHsp genes.
\end{abstract}

Results: In this study we characterized the function of a sHsp in abiotic stress tolerance in the moss Physcomitrella patens, a model for primitive land plants. Using suppression subtractive hybridization, we isolated an abscisic acidupregulated gene from P. patens encoding a $16.4 \mathrm{kDa}$ cytosolic class II sHsp. PpHsp16.4 was also induced by salicylic acid, dithiothreitol (DTT) and by exposure to various stimuli, including osmotic and salt stress, but not by oxidative stress-inducing compounds. Expression of the gene was maintained upon stress relief, suggesting a role for this protein in the recovery stage. PpHsp16.4 is encoded by two identical genes arranged in tandem in the genome. Targeted disruption of both genes resulted in the inability of plants to recover from heat, salt and osmotic stress. In vivo localization studies revealed that PpHsp16.4 localized in cytosolic granules in the vicinity of chloroplasts under non stress conditions, suggesting possible distinct roles for this protein under stress and optimal growth.

Conclusions: We identified a member of the class II sHsp family that showed hormonal and abiotic stress gene regulation. Induction of the gene by DTT treatment suggests that damaged proteins may act as signals for the stress-induction of PpHsp 16.4. The product of this gene was shown to localize in cytosolic granules near the chloroplasts, suggesting a role for the protein in association with these organelles. Our study provides the first direct genetic evidence for a role of a sHsp in osmotic and salt stress tolerance, and supports a function for this protein particularly during the stress recovery stage of $P$. patens.

Keywords: Small heat shock proteins, Osmotic stress, Salinity, Physcomitrella patens

\section{Background}

Plants must face and cope with various environmental stresses during their life cycle. Drought, salinity and exposure to extreme temperatures are serious threats to agriculture and have a great impact on plant productivity. Most of these stresses share common consequences as a result from water deprivation, namely osmotic stress and the associated oxidative stress [1].

\footnotetext{
* Correspondence: svidal@fcien.edu.uy

'Laboratorio de Biología Molecular Vegetal, Facultad de Ciencias, Universidad de la República, Iguá 4225, CP 11400 Montevideo, Uruguay

Full list of author information is available at the end of the article
}

Tracheophytes have evolved numerous anatomical adaptations to cope with water deficit. These include the presence of vascular tissues, root systems and stomata, which all together help minimizing water loss. By contrast, bryophytes lack these adaptations and must rely on efficient biochemical and physiological mechanisms to survive stress by limiting or repairing the cellular damage resulting from these conditions [2].

Numerous studies have shown that the plant hormone abscisic acid (ABA) plays a crucial role in controlling downstream responses essential for adaptation to abiotic stress. As part of osmotic stress responses, regulation of gene expression occurs in both ABA-dependent and

\section{Biomed Central}


ABA-independent manner [3]. Activation of ABA and stress responsive genes lead to accumulation of proteins belonging to different families, including components of the regulatory networks and proteins implicated in cellular defenses. The latter include proteins such as aquaporins, chaperones, enzymes for osmolyte biosynthesis or detoxification and late embryogenesis abundant (LEA) proteins [4].

Environmental stresses that result in cellular dehydration, such as salt, freezing and water stress lead to similar changes in plant gene expression [5-7]. Disruption of cellular homeostasis induced by exposure to these stresses often causes protein dysfunction. Therefore, cells must employ efficient mechanisms to allow proteins to maintain their functional conformation as well as to prevent the aggregation of denatured proteins under stress. One of the most widespread cellular responses to abiotic stress is the production of heat shock proteins (Hsps). They accumulate in both prokaryotic and eukaryotic cells in response to heat or exposure to various other stress conditions. Strong evidences support a role for Hsps as molecular chaperones, preventing protein aggregation or assisting protein folding during stress [8-12]. Hsps are grouped into five families according to their approximate molecular weight: Hsp100s, Hsp90s, Hsp70s, Hsp60s and Hsp20s, also known as small Hsps (sHsps). Small Hsps belong to a diverse and ubiquitous family of stress proteins that range in size from $12-42 \mathrm{kDa}$, and are defined by the presence of a conserved C-terminal $\alpha$-crystallin domain [13]. Plant sHsp protein family is far more complex than that in any other organism investigated to date, probably reflecting a molecular adaptation to stress conditions that are unique to plants [8]. For instance, the Arabidopsis genome encodes 19 sHsps which are divided into several subfamilies according to their sequence relatedness and their subcellular localization [8]. Angiosperms have 11 subfamilies that include most but not all of the sHsps. Six of the subfamilies are cytosolic/nuclear localized sHsps (CI-CVI) whereas five others are targeted to organelles: endoplasmic reticulum (ER), peroxisomes (PX), chloroplasts $(\mathrm{CP})$ and mitochondria (MTI and MTII) $[8,14,15]$.

Plant sHsps have been shown to accumulate in response to a broad spectrum of stress factors, such as heat, drought, salinity, low temperature and oxidative stress [8,12,16-21]. Moreover, some members of the cytosolic CI and CII sHsps have been shown to be constitutively expressed in the resurrection plant Craterostigma plantagineum, but not in the desiccation-sensitive callus, strongly suggesting a protective role for these proteins during desiccation [19]. Although they are usually not detected under normal growth conditions, several members of the sHsp protein family are developmentally regulated, being the most extensively characterized example of this non-stress regulation during seed development [22]. Developmental regulation of sHsps is generally restricted to some members of the class I and class II sHsps, suggesting that these proteins have distinct regulatory controls during seed maturation as opposed to during stress [23].

Stress-induced expression of sHsps is controlled by heat shock transcription factors (Hsfs) which bind to highly conserved palindromic motifs, so-called heat stress- elements (HSEs) [24-26]. Unlike most other organisms, plant Hsf gene family is highly complex, usually consisting in more than 20 members with high functional diversification [27]. Some members of the Hsf protein family are essential for expression of Hsps during certain developmental stages. This is the case of HsfA9 from Arabidopsis which controls accumulation of Hsps during seed maturation. Expression of Arabidopsis HsfA9 has been shown to depend on the ABSCISIC ACID INSENSITIVE 3 (ABI3) transcription factor, which regulates various genes during seed desiccation [28]. Furthermore, ABI3 is required for Arabidopsis developmental regulation of $H s p 17.4$ but is not required for stress induction of this gene [23], reflexing the complexity of the regulatory network that control the expression of this type of genes.

The specific mechanisms by which sHsps confer cell protection are not fully understood. However, in recent years several studies have contributed to develop models showing how these proteins act [15]. Small Hsps have been shown to have the capacity to stabilize and prevent aggregation of non-native proteins via binding through hydrophobic interactions [10,29-33]. Although sHsps do not appear themselves to be able to refold non-native proteins, the current model for sHsps function is that their selective binding to unfolded proteins may facilitate subsequent ATP-dependent refolding by other chaperones [10,29-31,34]. Consistent with this idea, in vitro studies of Hsp18.1 from Pisum sativum as well as Hsp16.6 from Synechocystis sp PCC6803 showed that these proteins bind to unfolded proteins allowing their further refolding by Hsp70/Hsp100 complexes [35].

Although it is generally assumed that sHsps are directly involved in abiotic stress tolerance in plants, much of the information available to date is based on in vitro assays, mainly due of the lack of gene-specific knockout mutants in sHps genes. Physcomitrella patens is an excellent model organism for investigating the role of individual genes by reverse genetics, due to the high frequency of homologous recombination that facilitates the targeted disruption of nuclear genes [36]. In higher plants, disrupted individual genes are usually obtained by screening of random mutants and the probability of altering a specific gene depends very much on the size of the target sequence. Therefore, $P$. patens has significant advantages over other model plants for functional studies of small genes, such as sHsps, by gene targeting 
via homologous recombination. In addition to this, several studies have shown that $P$. patens is highly tolerant to dehydration, salinity, and other abiotic stress factors [37-40], and this tolerance is thought to be based on the mobilization of efficient defense and repair mechanisms in response to stress and during stress relief [38].

This study addressed the question of the function of the duplicated $s H s p$ genes PpHsp16.4 in abiotic stress tolerance in $P$. patens, which was isolated as an ABA-induced gene using suppression subtractive hybridization. PpHsp16.4 gene product was localized in the cytoplasm and showed to be phylogenetically related to the cytosolic class II family of sHsps. We demonstrated that knockout mutants of the two PpHsp16.4 genes lead to impaired or delayed recovery of plants from salt, osmotic and heat stress.

\section{Results}

Identification of an ABA-induced gene encoding a 16.4 kDa sHsp from Physcomitrella patens

In order to identify genes involved in tolerance to abiotic stress in $P$. patens, suppression subtractive hybridization was employed to construct a library enriched in ABA- induced sequences. One of the most abundant sequence in our subtractive library corresponded to a gene encoding a 16.4 kDa sHsp [GenBank: XP_001757324.1]. A search in the $P$. patens full sequence (v1.6) in the public database Phytozome v9.1 (www.phytozome.net) [41] showed that PpHsp16.4 is encoded by two identical nuclear genes, hereby named PpHsp16.4a [Phypa_428883] and PpHsp16.4b [Phypa_428984]. These genes are 100\% identical and exist in a tail-to-tail orientation with 7725 bp separating their stop codons, suggesting their origin from a single ancestral gene that most likely had undergone recent events of tandem duplication and inversion. The conserved $\alpha$-crystallin domain of sHsps was used as query to search the genome of $P$. patens, revealing the existence of 22 genes encoding sHsps. A list of $P$. patens $s H s p$ genes, their genomic location, and the deduced proteins with their predicted subcellular localization is shown in Table 1 . The phylogenetic relationship between the $s H s p$ gene family from $P$. patens, Arabidopsis and rice was analyzed using ClustalW sequence alignment [42] followed by the neighbor-joining algorithm employing the MEGA 5.05 program [43].

Table 1 Small Hsp family of Physcomitrella patens

\begin{tabular}{|c|c|c|c|c|c|c|c|c|}
\hline Protein & Transcript & Phypa_v1.6 & Phypa_v1.1 & Scaffold & 0 & ORF & MW_(kDa) & Loc \\
\hline PpHsp21.5 & Pp1s129_85V6.1 & Phypa_444537 & Phypa_216427 & Scaffold 129:..572968..-..574083 & + & 190 & 21.5 & nuc/cyto \\
\hline PpHsp20.1 & Pp1s20_253V6.1 & Phypa_427505 & Pp1s20_253V6.1 & Scaffold 20:..1742974..-..1743985 & + & 180 & 20.1 & cyto \\
\hline PpHsp19.4 & Pp1s350_28V6.1 & Phypa_458371 & Phypa_199029 & Scaffold 350:..287956..-..288477 & + & 173 & 19.4 & cyto \\
\hline PpHsp19.2 & Pp1s50_96V6.1 & Phypa_74946 & Phypa_74946 & Scaffold 50:..1002205..-..1002857 & + & 169 & 19.2 & cyto \\
\hline PpHsp22.0 & Pp1s194_15V6.1 & Phypa_220338 & Phypa_220338 & Scaffold 194:..62465.....63601 & - & 195 & 22.0 & cyto \\
\hline PpHsp22.5 & Pp1s77_290V6.1 & Phypa_438264 & Phypa_38520 & Scaffold 77:..1524105..-..1525479 & + & 203 & 22.5 & chlo \\
\hline PpHsp18.4b & Pp1s144_148V6.1 & Phypa_446028 & Phypa_138125 & Scaffold 144:..1053435..-..1053920 & + & 161 & 18.4 & cyto \\
\hline PpHsp18.4a & Pp1s11_289V6.1 & Phypa_425098 & Phypa_114905 & Scaffold $11: . .2264806 . .-.2266292$ & + & 161 & 18.4 & cyto \\
\hline PpHsp13.4 & Pp1s182_60V6.1 & Phypa_141732 & Phypa_141732 & Scaffold 182:..494077.....494645 & + & 121 & 13.4 & cyto \\
\hline PpHsp12.5 & Pp1s3_114V6.1 & Phypa_64616 & Phypa_64616 & Scaffold 3:..718664..-..719270 & - & 111 & 12.5 & nucl \\
\hline PpHsp16.4b & Pp1s27_332V6.1 & Phypa_428984 & Phypa_70357 & Scaffold 27:..2270773.....2272356 & - & 147 & 16.4 & cyto \\
\hline PpHsp16.4a & Pp1s27_331V6.1 & Phypa_428883 & Phypa_205434 & Scaffold 27:..2261849..-..2263432 & + & 147 & 16.4 & cyto \\
\hline PpHsp17.2c & Pp1s85_11V6.1 & Phypa_439482 & Phypa_213039 & Scaffold 85:..60370..-..61284 & - & 154 & 17.2 & cyto \\
\hline PpHsp17.3b & Pp1s372_62V6.1 & Phypa_459035 & Phypa_199515 & Scaffold 372: 273630 - 274513 & + & 154 & 17.3 & cyto \\
\hline PpHsp17.8 & Pp1s380_17V6.1 & Phypa_459300 & Phypa_37582 & Scaffold 380:..166713..-..167180 & + & 155 & 17.8 & cyto \\
\hline PpHsp17.6 & Pp1s105_133V6.1 & Phypa_442034 & Phypa_133671 & Scaffold 105:..890756.....891525 & + & 156 & 17.6 & cyto \\
\hline PpHsp17.3a & Pp1s8_86V6.1 & Phypa_424252 & Phypa_174654 & Scaffold 8: 747337 - 748527 & + & 155 & 17.3 & chlo \\
\hline PpHsp17.2b & Pp1s8_249V6.1 & Phypa_424267 & Phypa_158998 & Scaffold 8:..2505191.....2506195 & - & 153 & 17.2 & chlo \\
\hline PpHsp17.2d & Pp1s8_209V6.1 & Phypa_424256 & Phypa_65913 & Scaffold 8:..2007522.....2008526 & + & 153 & 17.2 & chlo \\
\hline PpHsp17.2a & Pp1s8_244V6.1 & Phypa_424313 & Phypa_113859 & Scaffold 8:..2415925..-..2416902 & + & 153 & 17.2 & chlo \\
\hline PpHsp27.5 & Pp1s97_106V6.1 & Phypa_440946 & Phypa_81689 & Scaffold 97: 716468 - 718213 & + & 246 & 27.5 & chlo \\
\hline PpHsp27.3 & Pp1s38_338V6.1 & Phypa_72790 & Phypa_72790 & Scaffold 38: 1916174 - 1917189 & + & 242 & 27.3 & mito \\
\hline
\end{tabular}

Protein names were assigned according to their molecular weight (MW) in kiloDaltons (kDa) of the deduced proteins. Transcript name and the Phypa number from Phytozome database are listed for the Phycomitrella patens genome v1.1 and the genome v1.6. Scaffold values represent the genomic position of the genes. O: orientation, ORF: number of amino acids from the open reading frame, Loc: deduced subcellular localization (nuc: nuclear; cyto: cytosolic; chlo: chloroplastic). 
Based on the amino acid sequence homologies, this study clearly placed PpHsp16.4a and PpHsp16.4b in the same group with the cytosolic class II sHsps (Figure 1).

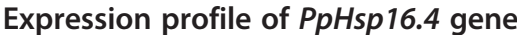

To gain insight into the role of PpHsp16.4 during different stress responses, we monitored transcript levels of the genes encoding this protein in moss gametophyte colonies exposed to different stress conditions or treated with various hormones or chemical compounds producing cellular stress. The genomic sequences of the transcribed regions of PpHsp16.4a and PpHsp16.4b are identical, including $100 \%$ identity in the first 700 bp promoter region, suggesting that the expression of these genes is similar to each other. RNA samples were prepared from controls and from plants treated with the hormones $\mathrm{ABA}$, salicylic acid (SA), and the oxidative stress-inducing compounds $\mathrm{H}_{2} \mathrm{O}_{2}$ and methyl viologen (MV). DTT was included in these experiments as a chemical causing protein misfolding. Plants were also exposed to osmotic stress on mannitol containing plates, to salinity, heat $\left(37^{\circ} \mathrm{C}\right)$, UV-B or to strong light conditions. All treatments were performed for $24 \mathrm{~h}$, except for the exposure to strong light, which was done for two hours. Transcript levels of $\mathrm{PpHsp} 16.4$ were analyzed by Northern hybridization using the full length cDNA sequence as a probe (Figure 2A). The detection of a unique hybridization band and the fact that non target sequences corresponding to other $s H s p$ genes have generally only short stretches of high sequence identity to PpHsp16.4, suggest the lack of cross-hybridization of the cDNA probe to homologous mRNA species. PpHsp16.4 was found to be constitutively expressed at relatively low levels in control gametophytes. These results were consistent with the microarray based expression data from P. patens genes, available at Genevestigator [44] (https:// www.genevestigator.com). Analysis of the digital expression profiles of different developmental stages of $P$. patens, showed that $P p H s p 16.4$ transcripts were expressed at relatively high levels during the gametophyte and sporophyte stages. Although most transcripts of the $s H s p$ gene family were found to be present at some level under non stress conditions during specific stages of the plant's life cycle, only two other transcripts, corresponding to the genes PpHsp19.2 and PpHsp18.4b, were found to be abundant during all developmental stages (Additional file 1), suggesting that these particular members of the Hsp gene family may play a role under normal plant growth.

In addition to the observed basal expression in unstressed plants, PpHsp16.4 was strongly induced by treatment with ABA, SA and DTT and after exposure of plants to heat, strong light, and salt or osmotic stress. In contrast, no increase in mRNA levels of PpHsp16.4 was observed in response to UV-B or to the oxidative stress inducing compounds, $\mathrm{H}_{2} \mathrm{O}_{2}$ or the herbicide $\mathrm{MV}$, which is a superoxide anion propagator. Similarly, treatment of plants with these compounds for shorter or longer periods of time ( $4 \mathrm{~h}$ and $48 \mathrm{~h}$ ) failed to induce PpHsp16.4 gene expression (Additional file 2), supporting that oxidative stress does not play a major role in the regulation of PpHsp16.4 gene expression. This later results were somewhat unexpected, as most of the CI and CII sHsp genes from other plants species are induced by oxidative stress [15].

Small Hsps have been suggested to be important not only during stress conditions, but also during plant recovery from stress [34]. This prompted us to analyze the expression of $\mathrm{PpHsp16.4}$ upon relief from heat or osmotic stress (Figure 2B). Plants were incubated at $37^{\circ} \mathrm{C}$ or in mannitol containing plates for $48 \mathrm{~h}$, and thereafter transferred to optimal growth conditions for $6 \mathrm{~h}$. In these experiments we used higher concentrations of mannitol for imposing a more severe osmotic stress, as these conditions have previously proven to be suitable for the evaluation of the $P$. patens capacity to recover from osmotic stress [37]. Expression of PpHsp16.4 was compared to the dehydrin $P p D H N A$, which was previously shown to be strongly induced by osmotic stress but rapidly repressed upon stress relief $[37,45]$. Our results showed that, in contrast to $P p D H N A$, relatively high expression levels of PpHsp16.4 were still observed after plants returned to optimal conditions, suggesting that PpHsp16.4 plays a role also during stress recovery.

Recently, Khandelwal et al [46] demonstrated that $\mathrm{ABI} 3$ is required for ABA-dependent recovery of $P$. patens from severe dehydration. Stress treatment of abi3 knockout plants resulted in a small or no reduction of the expression of several genes associated with stress tolerance. However, transcript accumulation of most of the assayed genes was drastically compromised in the abi3 mutant upon stress relief, suggesting that ABI3 is required primarily for stress recovery. These results prompted us to investigate the biological relevance of $\mathrm{ABI} 3$ in the regulation of PpHsp16.4 expression. We used a null mutant line of $P$. patens abi3 which contains no detectable ABI3 due to the disruption of the three copies of the gene [46]. Our

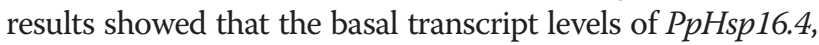
observed during normal growth, were considerably reduced in abi3 compared to the wild type. However, the expression profile of PpHsp16.4 was very similar in wild type and abi3 genotypes, both during stress as well as upon stress relief. In contrast, $P p D H N A$ transcript accumulation in response to osmotic stress was markedly compromised in the abi3 mutant, suggesting that different pathways regulate the stress-induced expression of these two genes (Figure 2B). Our results suggest that, in contrast to other stress responsive genes, the stress induction 


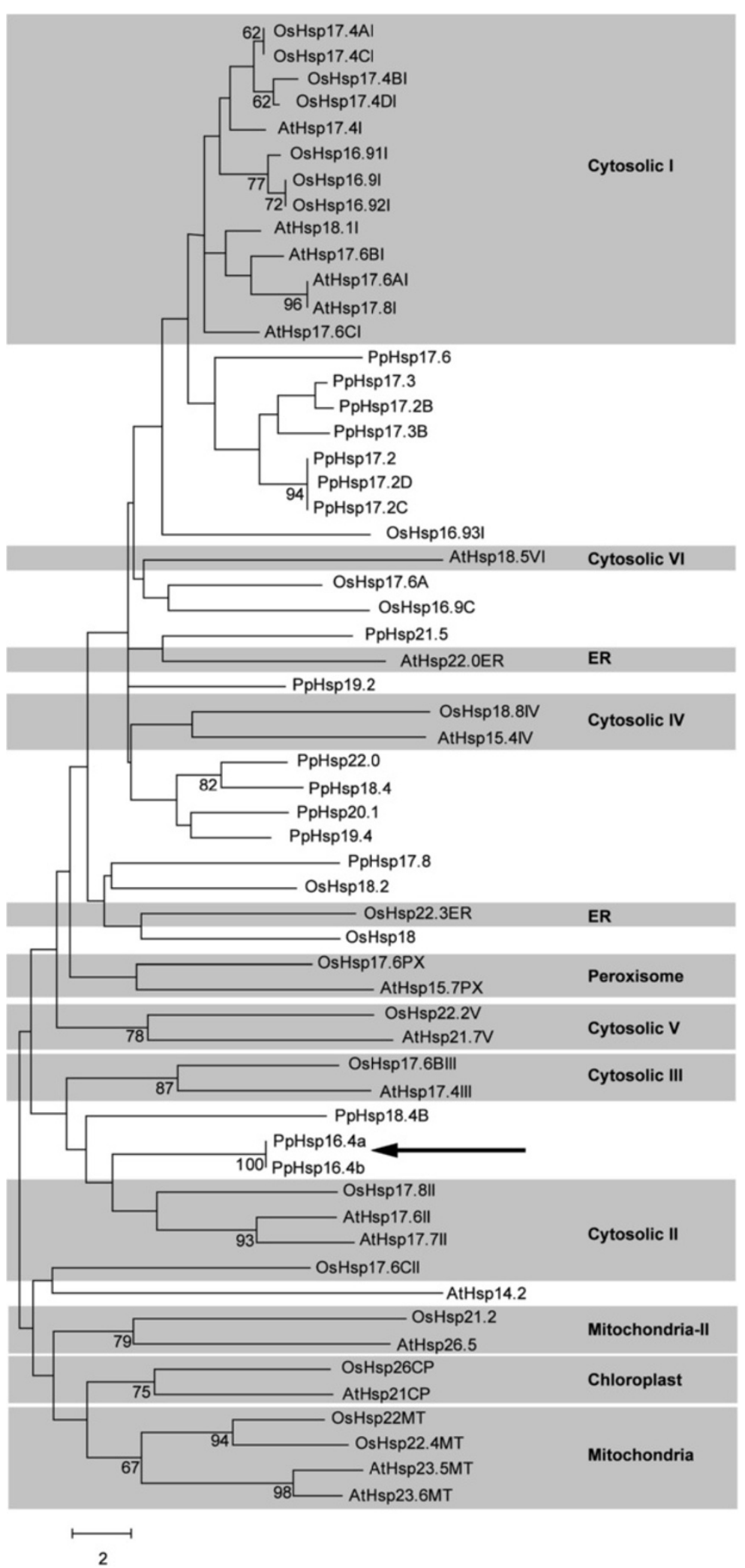

Figure 1 (See legend on next page.) 
(See figure on previous page.)

Figure 1 Phylogenetic analysis of the deduced sHsps of Arabidopsis, rice and P. patens. Full-length amino acid sequences were aligned by the CLUSTAL W and a phylogenetic tree was constructed by the neighbor-joining method using MEGA version 5. Accession numbers of the genes from Arabidopsis and rice are listed in Methods. P. patens sHsps are listed in Table 1. Numbers at branch nodes represent the confidence level of 1000 bootstrap replications. The abbreviations of species are as follows: At: Arabidopsis thaliana, Os: Oryza sativa and Pp: Physcomitrella patens. Arabidopsis and rice sHsps are separated into different subclasses which are highlighted in grey squares. ER (endoplasmic reticulum). Arrow shows PpHsp16.4a and PpHsp16.4b from P. patens.

and maintenance of $\mathrm{PpHsp} 16.4$ gene expression in P. patens is regulated in an ABI3 independent manner.

\section{PpHsp16.4 localized in cytosolic granules}

To determine the intracellular localization of PpHsp16.4 in heterologous cells, the coding region of the gene was fused in frame to GFP and expressed under the control of the constitutive CaMV 35S promoter (35S:PpHsp16.4GFP) in tobacco cells or in transgenic Arabidopsis plants (Figure 3A). As a control, a construct constitutively expressing GFP alone was used for transient expression in tobacco protoplasts (Figure 3A-I). Confocal microscopy showed that, while the fluorescent signal of non-fused GFP was found to be homogenously distributed in the cytosol of tobacco protoplasts, PpHsp16.4-GFP fusion proteins were present in agroinfiltrated tobacco leaves

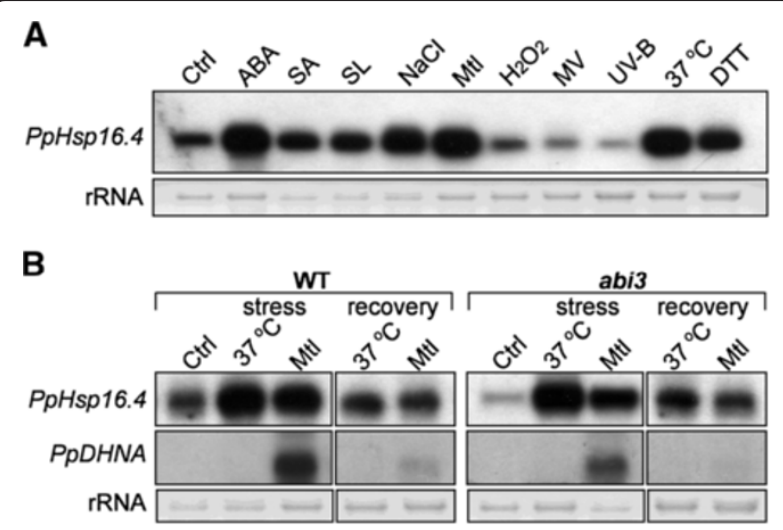

Figure 2 Expression of PpHsp16.4. (A) Total RNA was extracted from untreated control wild type plants (Ctrl), plants treated for 24 hours with $50 \mu \mathrm{M} \mathrm{ABA}, 1 \mathrm{mM} \mathrm{SA}, 500 \mathrm{mM}$ Mannitol (Mtl), $300 \mathrm{mM} \mathrm{NaCl}, 10 \mathrm{mM}$ DTT, $100 \mu \mathrm{M}$ methyl viologen (MV) and $100 \mu \mathrm{M} \mathrm{H}_{2} \mathrm{O}_{2}$. Samples were also obtained after 24 hours exposure to high temperature $\left(37^{\circ} \mathrm{C}\right), \mathrm{UVB}$, and after 2 hours of exposure to strong light (SL). Ten $\mu \mathrm{g}$ of RNA were analyzed by Northern blot using a ${ }^{32} \mathrm{P}$-labeled hybridization probe corresponding to the fulllength cDNA sequence of PpHsp 16.4. (B) Northern blot analysis of PpHsp16.4 and PpDHNA transcripts in wild type (WT) or abi3 mutant genotypes. Total RNA was extracted from untreated control plants (Ctrl), plants exposed to $37^{\circ} \mathrm{C}$ or incubated in medium supplemented with $900 \mathrm{mM}$ mannitol (Mtl). Samples were collected after two days of stress, and 6 hours of recovery. Full -length cDNA sequences of PpHsp16.4 and PpDHNA were ${ }^{32}$ P-labeled and used as hybridization probes. In all experiments, ethidium bromide staining of ribosomal RNA (rRNA) was used to ensure equal loading of RNA samples. and transfected protoplasts or in Arabidopsis transgenic lines, in round-shaped bodies of different diameters (Figure 3A-II to V). The heterogeneity in the size and the number of fluorescent structures suggested that, rather than targeted to an organelle, $\mathrm{PpHsp} 16.4$ forms large molecular mass structures within the cytoplasm.

To rule out that the observed localization pattern could result from the constitutive overexpression of PpHsp16.4 in heterologous systems, we examined in detail the targeting of fusion proteins expressed in their natural transcription and translation context in $P$. patens. For that purpose, we generated $P$. patens knock-in lines by inserting the Citrine yellow fluorescent protein gene [47] just before the stop codon of PpHsp16.4 by means of homologous recombination (Figure 3B). In this way, the expression of PpHsp16.4-Citrine chimeric gene was driven by its native promoter, and the spatiotemporal regulation of the fusion protein could be examined. Gene fusions were confirmed in stable transgenic lines by PCR using primers that recognized a sequence within the Citrine gene of the replacement construct combined with primers annealing with the genomic sequences flanking the $5^{\prime}$ region of the two identical PpHsp16.4a and PpHsp16.4b loci (Figure 3C). We selected three lines that were correctly targeted to the PpHsp16.4 locus based on the expected size of the PCR amplification products (1787 bp). Accumulation of the fusion protein in ABA-treated transgenic lines was analyzed by Western blot using $\alpha$-GFP antibodies (Figure 3D). A band of $\sim 43 \mathrm{kDa}$, consistent with the predicted size of PpHsp16.4-Citrine fusion protein was observed in all three lines. An additional band with a molecular mass of $27 \mathrm{kDa}$ was observed in all experiments and corresponded to the cleaved Citrine product. To determine whether the accumulation pattern of PpHsp16.4-Citrine fusion protein correlated with the expression pattern of the wild type PpHsp16.4 gene, transgenic knock-in lines were analyzed by Western blot for the presence of PpHsp16.4-Citrine after treatment with $\mathrm{ABA}$ or in response to various abiotic stress stimuli, including heat $\left(37^{\circ} \mathrm{C}\right)$, salt $(\mathrm{NaCl})$ or osmotic stress (mannitol). Accumulation of the fusion protein was also analyzed upon relief from heat stress, by incubating plants at $37^{\circ} \mathrm{C}$ for 48 hours, and thereafter transferring them to optimal growth conditions for 6 hours. All treatments resulted in higher accumulation of the fusion protein when compared to the controls, indicating that the targeted construct was properly regulated, 


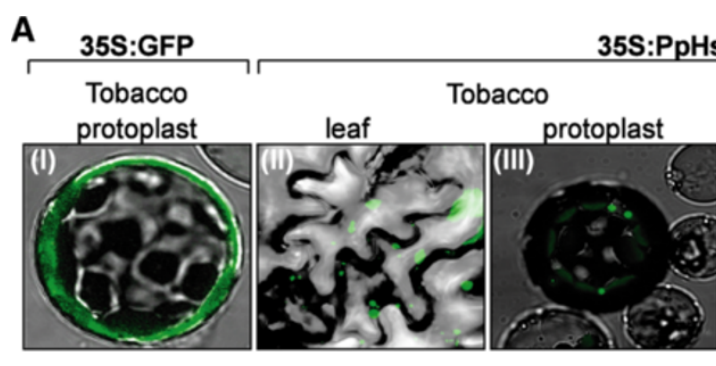

B

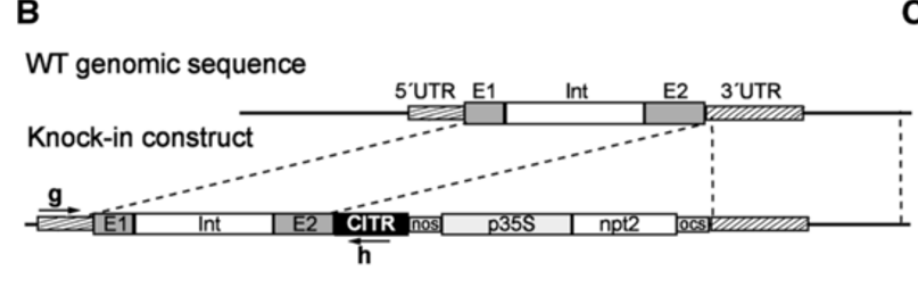

C

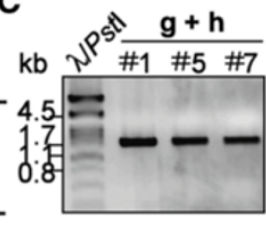

D

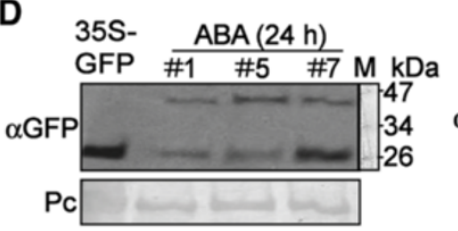

E

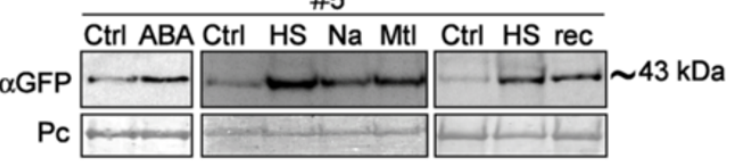

$\mathbf{F}$

protonema (Ctrl)

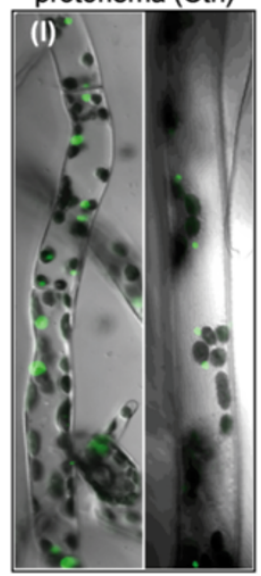

P. patens PpHsp16.4-Citrine\#5

gametophyte (Ctrl)
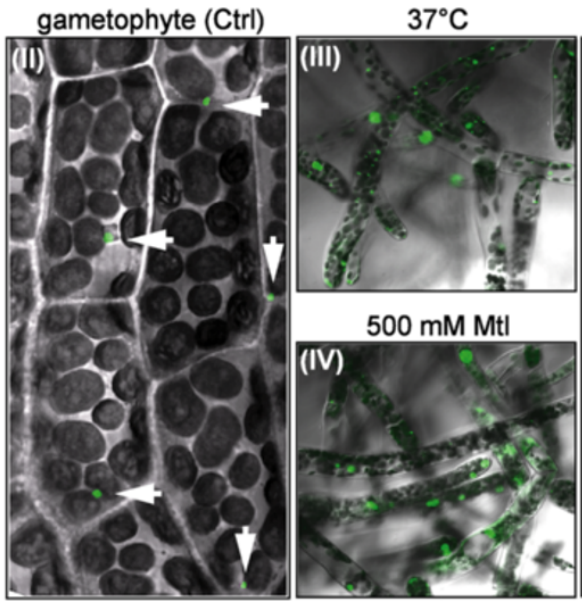

(V)

protoplasts

Figure 3 Subcellular localization of PpHsp16.4. (A) Confocal microscopy images of: tobacco protoplasts electroporated with 35S:GFP (I) or with 35S:PpHsp16.4-GFP constructs (II); tobacco leaves agroinfiltrated with 35S-PpHsp16.4-GFP construct (III); or Arabidopsis transgenic lines overexpressing PpHsp16.4-GFP fusion proteins (IV and V). (B) Schematic diagram of PpHsp16.4 genomic locus and knock-in construct. Exons (E1 and E2), intron (Int), coding sequence of Citrine (CITR), 5' and 3' untranslated regions (UTR), are shown. The position of the primers used for PCR analysis of transgenic lines is indicated by arrows. (C) PCR analysis of transgenic lines (\#1, \#5 and \#7) (D) Immunoblot detection of PpHSP16.4-Citrine fusion proteins in transgenic P. patens. Proteins extracted from lines \#1, \#5 and \#7, treated for 24 hours with $50 \mu \mathrm{M}$ ABA, were analyzed by Western blot using antibodies a-GFP. As a control, a protein sample from Arabidopsis expressing GFP was included (35S-GFP). Protein sizes in kDa of the molecular marker (M) are shown. Ponceau red (Pc) staining of Rubisco large subunit was used to ensure equal loading of protein samples (E) Immunoblot detection of PpHsp16.4-Citrine P. patens. Samples were prepared from controls (Ctrl) or from plants treated with $50 \mu \mathrm{M} \mathrm{ABA}$ or incubated with $300 \mathrm{mM} \mathrm{NaCl}(\mathrm{Na})$ or $500 \mathrm{mM}$ mannitol (Mtl) containing plates, or at $37^{\circ} \mathrm{C}$ (HS: Heat Shock), Right panel, plants incubated for 48 hours at $37^{\circ} \mathrm{C}(\mathrm{HS})$ and allowed to recover for 6 hours (rec). (F) Spatial regulation and subcellular localization of PpHsp16.4-Citrine fusion proteins transgenic line \# 5. Confocal microscopy images of untreated protonema (I), leafy gametophyte (II), protonema exposed for 24 hours at $37^{\circ} \mathrm{C}$ (III), protonema incubated in $500 \mathrm{mM}$ mannitol supplemented plates (IV) and protoplasts ( $V$ ). White arrows indicate Citrine fluorescence. Green image: GFP or Citrine emission, in red: chloroplast fluorescence, in gray: transmission light microscopy. 
and that transcript and protein levels of this gene exhibited similar expression patterns (Figure 3E). These transgenic lines were analyzed by confocal microscopy for the determination of the tissue and subcellular localization pattern of the fusion protein. Consistent with the localization analysis in heterologous systems, PpHsp16.4Citrine accumulated in well-defined regions of the cytoplasm of $P$. patens cells and was missing in other cellular compartments. One or few fluorescent bodies were observed in protoplasts from stable transgenic lines (Figure $3 \mathrm{~F}-\mathrm{V}$ ) and in plant cells from different tissues. These structures were found to be always located in the vicinity of chloroplasts when plants were grown under optimal conditions (Figure 3F-I, II). Fluorescent structures were usually more abundant in protonema tissue (Figure 3F-I) than in the leafy gametophyte (Figure 3F-II). Upon exposure to heat or osmotic stress, fluorescent structures became larger and were more abundant than in control cells (Figure 3F-III, IV), resembling the cytosolic granules described by Löw et al [12] in tomato plants exposed to prolonged heat stress.

\section{Targeted disruption of the two copies of PpHsp16.4 compromised stress tolerance}

To assess the function of PpHsp16.4 in stress tolerance, we used gene targeting to generate disruption mutants of PpHsp16.4 genes. As both genes are 100\% identical at the nucleotide level, a single knockout construct was used for gene replacement of PpHsp 16.4a and PpHsp16.4b by homologous recombination (Figure 4A). In this construct, most of the first exon and the intron of the target genes were replaced by a kanamycin selection cassette (nptII). Gene targeting events were identified by PCR to select lines in which insertion of the transgene had occurred either in one of the two genes, or in both genes in the same transformation event (Figure 4B). To identify insertion events in PpHsp16.4a, we used a reverse primer located within the selection cassette (primer c) together with a forward primer (primer a), located outside the gene targeting construct in a genomic region upstream of $\mathrm{PpH}$ sp16.4a, that has no homology to sequences upstream of PpHsp16.4b. Similarly, to identify insertion events within the PpHsp16.4b gene, we used a forward primer located within the selection cassette (primer c) together with a reverse primer (primer e) that binds a genomic region outside the construct, downstream of this gene. The expected sizes of the PCR products that would originate from specific gene targeting events at the loci PpHsp16.4a or PpHsp16.4b is of 1353 bp or 1378 bp, respectively.

Several lines were obtained in which either PpHsp16.4a or PpHsp16.4b had been targeted (data not shown). Two independent lines ( $\mathrm{dKO}-1$ and $\mathrm{dKO}-2)$ were identified, in which homologous recombination had occurred at the 5' end of both PpHsp16.4a and PpHsp16.4b loci (Figure 4B).
To analyze whether these lines had incorporated the construct by two events of homologous recombination, primers were designed to recognize specific sequences outside the construct, downstream of PpHsp16.4a (primer b) or of $P p H s p 16.4 b$ (primer f). When these primers were used in combination with a primer located within the selection cassette (primer d), no PCR product was observed in any of the lines analyzed. This result could be indicative of an integration pattern derived from a HR event at one end and a non-homologous end joining event at the other. To investigate whether a wild type copy of the targeted locus remained adjacent to the inserted construct, we used the primers that recognize genomic sequences flanking the construct of either PpHsp16.4a (primers a and b) or PpHsp16.4b (primers $\mathrm{f}$ and e). PCR products from the expected sizes (3882 bp PpHsp16.4a and 4024 bp for PpHsp16.4b) were obtained from the wild type genotype, but no amplification was observed when using DNA from any of the dKO lines, indicating the absence of a full wild type copy of these genes in the double mutants (Figure 4C).

Complex integration patterns, derived from concatenation of DNA or from other possibilities, have been shown to occur frequently when transforming $P$. patens genome with a targeting vector [48]. To analyze the nature of the DNA integration within PpHsp16.4a and PpHsp 16.4b loci in the double targeted lines, we used two outward-pointing primers (c and d) specific to the selection cassette to identify possible head-to-tail concatemers. A single PCR fragment of $1.3 \mathrm{~kb}$ was observed for the $\mathrm{dKO}-2$ line (Figure 4D). This fragment was cloned and sequenced and the results support a model where at least two copies of the construct DNA had integrated in a head-to-tail orientation, but with the loss of the 3' PpHsp16.4 genomic sequence. No PCR product was obtained when using a single primer only, indicating the absence of head-to-head or tail-to-tail full length concatemers (data not shown). A schematic representation of a possible integration pattern in either PpHsp16.4a or PpHsp16.4b loci in $\mathrm{dKO}-2$, is shown in Figure 4E. To determine whether the construct had integrated only at PpHsp16.4 loci or additional copies were introduced in other genomic locations, we performed Southern blot using part of the selection cassette as a probe (Figure 4G). Genomic DNA from the double KOs was digested with PstI or with BamHI restriction enzymes, which cleave within the selection cassette, at the positions shown in Figure 4A. If a single insertion had occurred in each of the target genes, four hybridization bands of 8.38, 4.58, 7.7 and $3.3 \mathrm{~kb}$ should be detected after Pst I digestion, and two bands of 5.4 and $4.7 \mathrm{~kb}$, after BamHI cleavage. The restriction pattern obtained with PstI resulted in two bands of 8.4 and $4.5 \mathrm{~kb}$ in both mutants. It is possible that the 7.7 and $3.3 \mathrm{~kb}$ bands were not detected due to the short area 


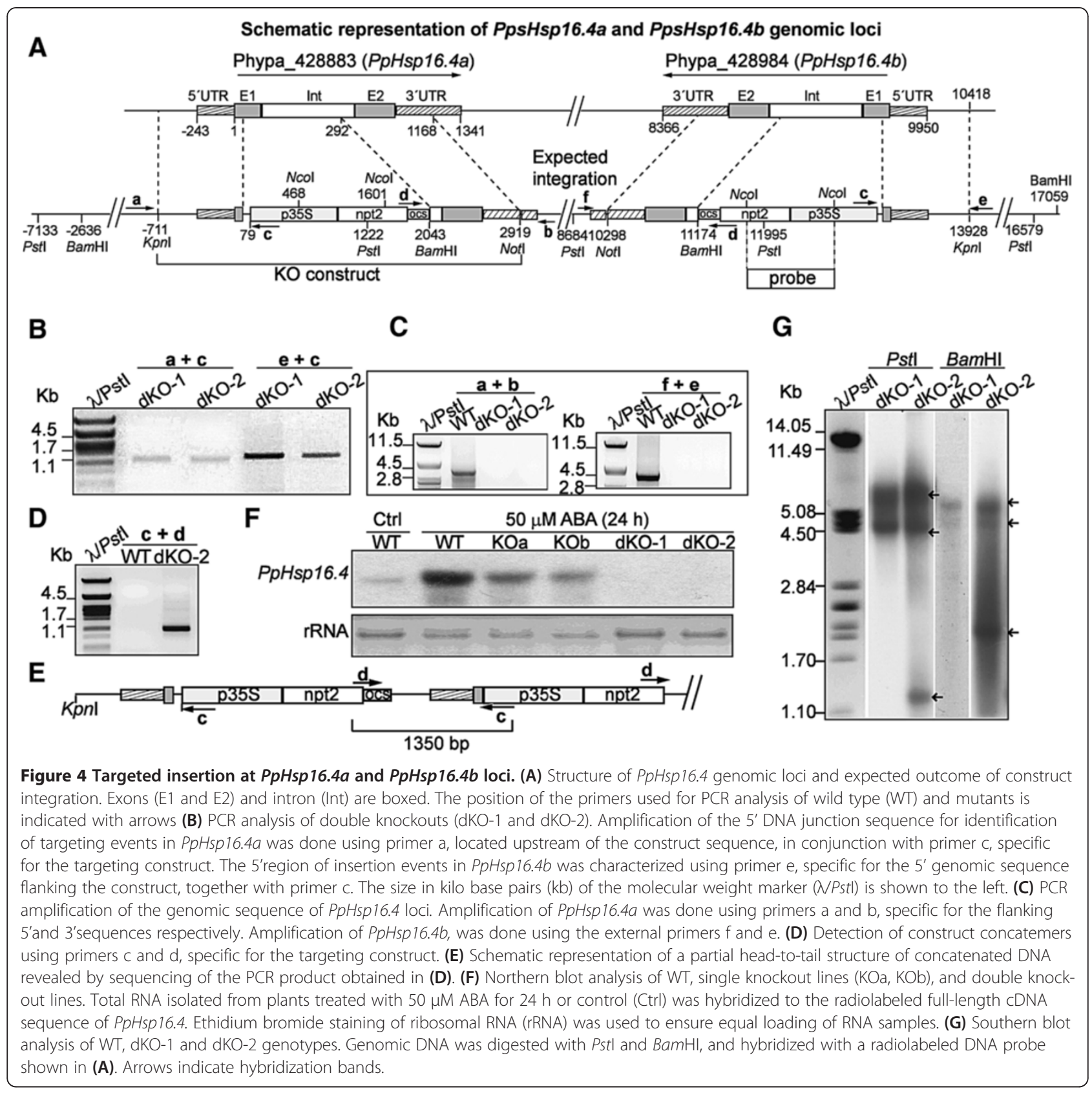

of coverage of the probe. In case of the dKO-2 line, an additional band of $1.5 \mathrm{~kb}$ was observed, supporting multiple integration events in the same locus. Digestion with BamHI produced two hybridization bands of 5.4 and $4.7 \mathrm{~kb}$ in both KOs and an additional band of $1 \mathrm{~kb}$ was observed in $\mathrm{dKO}-2$. These results suggest that no additional inserts had been integrated in other genomic regions outside of PpHsp16.4a and PpHsp16.4b loci in the double mutants, although a complex integration pattern, most likely involving the deletion of part of the DNA lying between both genes, had occurred for at least dKO-2 line.
To confirm the loss of function of $P p H s p 16.4$ in the KO lines, transcript accumulation of the $P p H s p 16.4$ genes was analyzed by Northern blot after ABA-treatment of wildtype and mutant genotypes. PpHsp16.4 transcript was lower in the single knockout mutants ( $\mathrm{KOa}$ and $\mathrm{KOb}$ ) than in wild-type plants and was completely eliminated in the double KO lines (Figure 4F). Single KOs ( $a$ and b) and the double KOs 1 and 2 lines were analyzed for phenotypic alterations during normal growth or stress conditions. In all conditions assayed, the phenotype of the two independent single disruption lines did not differed signi- 
ficantly from the wild type plants. Also, both double mutants were phenotypically indistinguishable from each other in our experiments and therefore only the data of $\mathrm{dKO}-1$ is shown in Figures 5 and 6. No phenotypic changes in growth rate or in developmental progression were observed in the single or in the double knockout mutants in standard growth conditions (Figure 5A, Ctrl). To obtain functional data on the role of PpHsp16.4 during stress conditions, we monitored growth and chlorophyll content of wild type and mutant lines exposed to various stress factors. No differences in the sensitivity to oxidative stress-inducing compounds, such as $\mathrm{H}_{2} \mathrm{O}_{2}$ and $\mathrm{MV}$, were observed between the wild type and the mutant lines (data not shown). In contrast, the double KO lines were unable to recover from prolonged heat (Figure 5) or from severe salt $(0.5 \mathrm{M} \mathrm{NaCl})$ or osmotic $(0.9 \mathrm{M}$ mannitol $)$ stress (Figures 6A and 6B). Whilst wild type plants usually displayed full recovery 17 days after returning to optimal growth conditions, little or no growth took place in the double KO lines. Under these conditions, chlorophyll content and dry weight of the double mutant was reduced by $50 \%$ when compared to the wild type plants. These results showed that PpHsp16.4 has an essential role in the recovery of $P$. patens from heat and from prolonged or severe salt and osmotic stress conditions.

\section{Discussion}

Abiotic stress-induction of PpHsp16.4 is independent of ROS and $\mathrm{ABI} 3$

This study provides genetic evidence for the involvement of a sHsp from $P$. patens in heat, salt and osmotic stress tolerance. PpHsp16.4 gene, which was found to be abundant in a subtractive library enriched in ABA-induced cDNAs, encodes a $16.4 \mathrm{kDa}$ protein belonging to the cytosolic class II subfamily of plant sHsps. PpHsp16.4 was shown to be expressed at low levels under optimal growth conditions, and up-regulated in response to exposure to various abiotic stress factors, including strong light, heat, salt and osmotic stress. These stresses are usually accompanied by oxidative cell damage due to the accumulation of ROS, and therefore, it has been suggested that these compounds play an important role in $s H s p$ gene regulation [49]. Consistent with this, many of the CI or CII sHsp encoding genes from Arabidopsis and from other angiosperms, are expressed in response to oxidative stress among a broad spectrum of other stressors [15,22,50-53]. Furthermore, heat shock transcription factors have been shown to sense ROS and in turn activate $H s p$ gene expression [54,55], and some data suggest that Hsps protect cells against ROS [20,56]. However, in our experiments, expression of PpHsp16.4

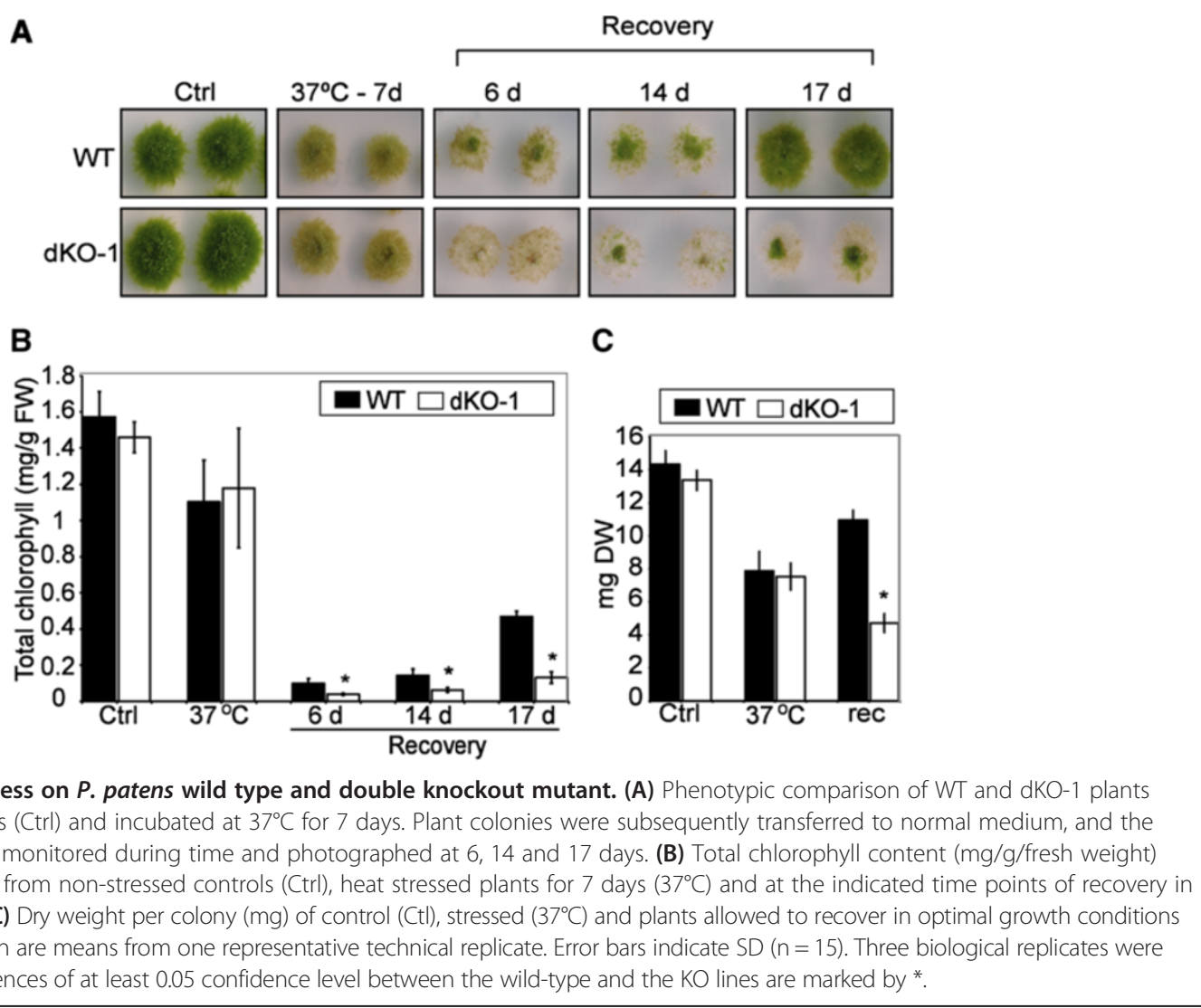



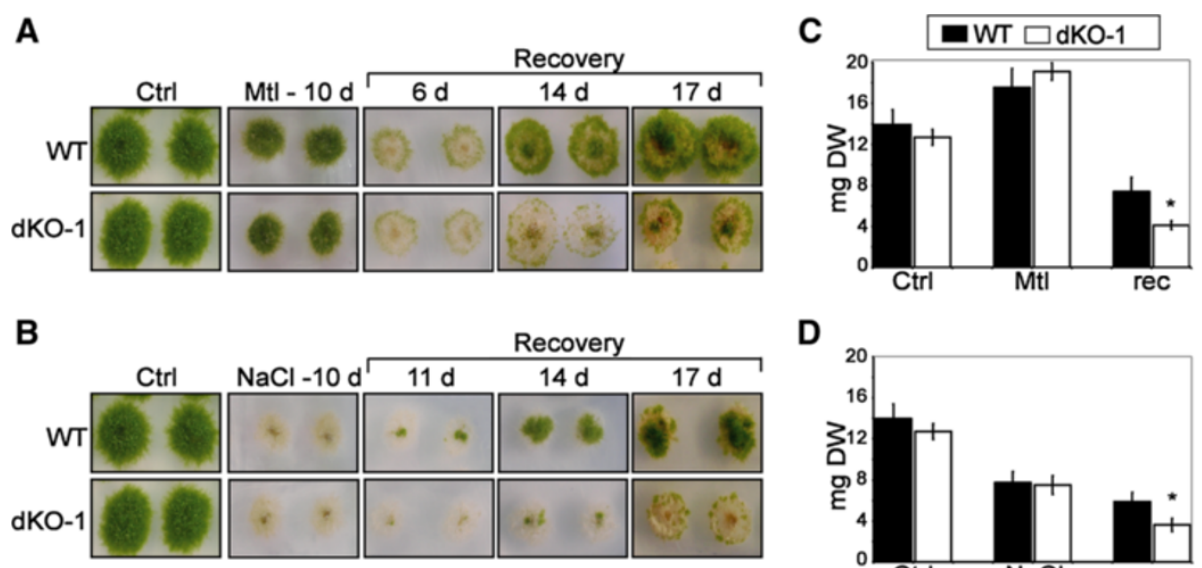

D

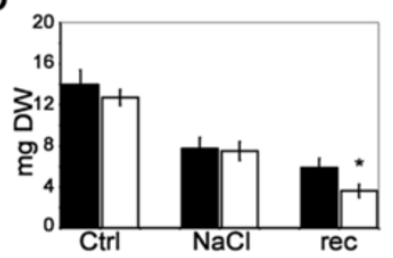

E

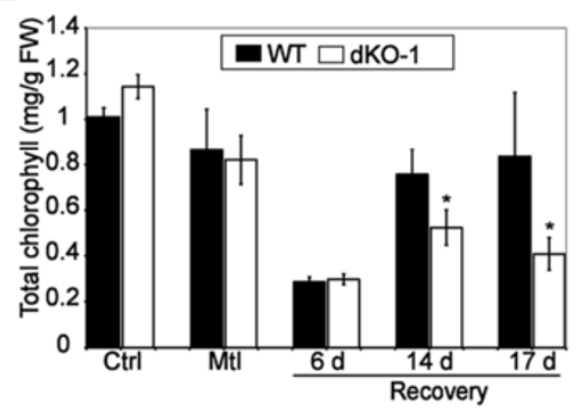

$\mathbf{F}$

Figure 6 Effect of osmotic and salt stress on P. patens wild type and knockout mutant. (A) Photograph images of WT and dKO-1 lines grown in optimal conditions (Ctrl), incubated for 10 days in plates supplemented with $900 \mathrm{mM}$ mannitol (Mtl-10 d), and during 6, 14 and 17 days of recovery from osmotic stress. (B) Same as above but employing $500 \mathrm{mM} \mathrm{NaCl}$ as stressor and 11, 14 and 17 days of recovery. (C) Dry weight per colony in milligrams (mg) of controls (Ctl), plants stressed with $900 \mathrm{mM}$ Mannitol for 10 days (Mtl) and plants allowed to recover from stress for 17 days (rec). (D) Same as (C) but using 500 mM NaCl as stressor. (E) Total chlorophyll content (mg/g/fresh weight) per colony from nonstressed controls (Ctrl), mannitol stressed plants (Mtl) and from plants allowed to recover from stress at the indicated time points in days. (F) Same as above but using $\mathrm{NaCl}$ as stressor. The values shown are means from one representative technical replicate. Error bars indicate SD $(n=15)$. Three biological replicates were carried out. Significant differences of at least 0.05 confidence level between the wild-type and the KO lines are marked by *

gene was not affected by $\mathrm{H}_{2} \mathrm{O}_{2}$ or by the herbicide methyl viologen, indicating that ROS are not the primary signals for the induction of this particular gene. In contrast, induction of the unfolded protein response by treatment of plants with DTT resulted in a strong accumulation of PpHsp16.4 transcripts, suggesting that rather than ROS themselves, the damaged proteins may act as signals for gene induction, as it has been previously suggested [57].

In addition to stress, PpHsp16.4 was induced by treatment with ABA and SA, two phytohormones that have been linked to heat stress signaling and basal thermotolerance in plants $[58,59]$. SA has been shown to induce the expression of sHsp genes from Arabidopsis [60,61] and $P$. patens [62], suggesting a conservation of this regulatory pathway between angiosperms and mosses. Elevated levels of both ABA and SA have been measured in various plant species in response to heat stress $[58,60,63]$, although their role in the regulation of Hsp gene expression during heat stress is not clear $[59,64]$.

A recent report demonstrated that PpABI3 was essential during the plant's recovery from stress for maintenance of transcripts encoding proteins that are critical for tolerance [46]. The high expression levels of PpHsp16.4 observed when plants were transferred to optimal conditions after exposure to stress, suggests a role for the corresponding protein in the recovery stage. However, expression of PpHsp16.4 during stress and upon stress relief was ABI3-independent. Nevertheless, the basal expression of the gene under optimal growth conditions was reduced in abi3 mutant, suggesting that different regulatory pathways operate in the regulation of PpHsp16.4 and supporting distinct developmental and stress regulation pathways of sHsps, as previously suggested [23]. These results also suggest that PpHsp16.4 may be involved in cellular functions under non-stress 
conditions as it has been suggested for several members of the plant $s H s p$ gene family that exhibit constitutive expression under non-stress conditions in various developmental stages $[51,65]$.

\section{A functional PpHsp16.4 gene is required for recovery from heat, salt and osmotic stress.}

Elucidation of plant sHsp function in vivo has been challenging due to the limited T-DNA insertion lines that are available in Arabidopsis to facilitate the analysis of sHsp deficient plants. The possibility to carry out targeted gene disruption in $P$. patens by means of homologous recombination, allowed us to assess the role of PpHsp16.4 genes in stress tolerance, by generating single and double knockout mutants of these genes. Our results showed that although wild type plants normally exhibit a low but constitutive expression level of PpHsp16.4 under optimal growth, we were not able to detect any significant difference in growth or morphology between the wild type and any of the mutant genotypes during nonstress conditions. Moreover, no phenotypical differences in the stress response were observed between the wild type and the single and double knockout mutants when growing in the presence of high salt or osmotic stress, or after incubation at $37^{\circ} \mathrm{C}$. Nevertheless, we were able to detect a clear phenotype in the double knockout plants at the stress recovery stage. When plants exposed to heat, salt or osmotic stress were transferred to optimal growth medium, the double knockout lines were affected or failed completely to resume growth. Our data is consistent with other studies showing that $P$. patens, like other bryophytes, survives stress by employing molecular mechanisms that protect cellular integrity during stress and enable damage repair upon stress relief allowing plants to resume growth $[37,39,46]$. In this context, in accordance to the current models for sHsp action [15], PpHsp16.4 may contribute to stress tolerance by preventing stressinduced irreversible protein aggregation and, together with other chaperones, help re-solubilizing aggregated proteins allowing cells to return to equilibrium during recovery. It is intriguing that such phenotypic alterations were observed in spite of the large number of $s H s p$ genes present in $P$. patens and the possible redundancy in their function.

\section{Subcellular localization of $\mathrm{PpHsp} 16.4$ reveals possible distinct roles for this protein during stress and under physiological conditions}

The generation of $P$. patens knock-in lines expressing the Citrine fluorescent protein fused to the C-terminal end of PpHsp16.4, allowed us to examine the subcellular localization and the spatiotemporal regulation of the fusion protein, when driven by the native promoter of the gene. PpHSP16.4 was expressed in all tissues under normal growth conditions as shown by the presence of single or multiple fluorescent bodies within the cytoplasm of the cells. Interestingly, these structures were always located in the vicinity of chloroplasts, suggesting a possible role for this protein in association with chloroplast functions. Chloroplasts are the primary targets of damage caused by high light, which interferes with oxygenic photosynthesis, a phenomenon known as photoinhibition [66], and exposure of plants to excess light strongly induced PpHsp16.4 transcript accumulation. Moreover, a recent report has demonstrated that a cytosolic class I Arabidopsis Hsp17.8 plays a role under standard physiological conditions, in targeting proteins to the outer membranes of chloroplasts [67]. These authors showed that in non-stressed cells, Arabidopsis sHsp17.8 acts as an ankyrin repeat protein 2A (AKR2A) cofactor and binds chloroplasts as a dimer assisting protein targeting to this organelle. However, under heat shock conditions, expression of the gene was strongly induced and Hsp17.8 was converted to high oligomeric forms, as shown for other sHsps. Using heterologous tobacco and Arabidopsis transient or stable expression systems, we showed that PpHsp16.4 localized in the cytoplasm under the form of large and shapeless structures, resembling the heat-induced granules described by Löw et al [12]. The observed fluorescent structures probably represent oligomeric complexes of PpHsp16.4-GFP fusion proteins, as it is well known that plant sHsps form oligomers of different orders $[15,68]$. The expression profile of PpHsp16.4 in P. patens supported a similar pattern as for the Arabidopsis sHsp17.8. Indeed, upon heat shock or osmotic stress, the expression of PpHsp16.4 was strongly induced both at the transcript and the protein level, and the cytosolic signals of the fusion protein were converted to large structures which are consistent with high oligomeric protein complexes. This supports the idea that when acting as chaperones in the stress response, PpHsp16.4 could bind to unfolded proteins in large complexes, thereby preventing them from forming nonspecific aggregates, as it has been proposed for $\mathrm{sHsp}$ function [33].

\section{Conclusions}

Since the development of $P$. patens as a model system for reverse genetics by using homologous recombination technologies, numerous studies have contributed to genetically dissect plant responses to environmental stress. Despite the significant amount of data concerning the structure, gene regulation and function of the plant $s H s p$ gene family, attributing specific roles to individual proteins in stress tolerance has been difficult. Using this excellent model, we provide the first direct genetic evidence for a role of a sHsp in osmotic and salt stress tolerance. Our results support a function of this protein particularly 
during the stress recovery stage of $P$. patens, emphasizing the importance of cellular mechanisms that protect protein integrity and enable damage repair upon stress relief. Our results also suggest a role for this sHsp under non stress conditions, in association with chloroplasts, as it has been shown for some class I sHsps from Arabidopsis.

\section{Methods}

Plant material, growth conditions and stress treatments Physcomitrella patens Grandsen wild type [69] was used for all experiments described in this study. The abi3 triple knockout mutant [46] was kindly provided by Prof. Ralph S. Quatrano. Plants were grown and maintained axenically on cellophane overlaid BCDAT medium $\left(1.6 \mathrm{~g} \mathrm{~L}^{-1}\right.$ Hoagland's $1 \mathrm{mM} \mathrm{MgSO}_{4}, 1.8 \mathrm{mM} \mathrm{KH}_{2} \mathrm{PO}_{4} \mathrm{pH}$ 6.5, $10 \mathrm{mM}$ $\mathrm{KNO}_{3}, 45 \mu \mathrm{M} \mathrm{FeSO}_{4}, 1 \mathrm{mM} \mathrm{CaCl}, 5 \mathrm{mM}$ ammonium tartrate and $10 \mathrm{~g} \mathrm{~L}^{-1}$ agar) as described by Ashton and Cove [70]. To generate protonemal cultures plant material was macerated with a sterile mortar and pestle in $2 \mathrm{ml}$ of sterile double distilled water. For micropropagation, moss colonies were cut with a scalpel and plant fragments were transferred to fresh medium with cellophane. All plants were grown at $22^{\circ} \mathrm{C}$ under a photoperiod of 16 hours light, with a photon flux of $60 \mu \mathrm{mol} \mathrm{m} \mathrm{mec}^{-1}$. Three weeks-old colonies were used for all experiments. Abscisic acid, $\mathrm{H}_{2} \mathrm{O}_{2}$, methyl viologen, salicylic acid, dithiothreitol, $\mathrm{NaCl}$ and mannitol treatments were incorporated in the BCDAT medium. The concentrations of these compounds are indicated in the figure legends. Strong light treatment was performed by exposing the colonies with a photon flux of $350 \mu \mathrm{mol} \mathrm{m} \mathrm{sec}^{-1}$. UV-B treatment was done using a HiTech lamp (G25T8E, Japan) with UV-B $0.034 \mathrm{~mW} / \mathrm{cm}^{2}$. All treatments were performed for 24 hours except for strong light that was performed for 2 hours. All experiments were repeated at least three times. The different plant genotypes were grown together in the same plate, five colonies per genotype, and five plates per treatment and time point.

Tobacco plants of Nicotiana tabacum cv Petit Havana [71] was used for transient expression analysis. For protoplast preparation, plants were grown from surfacesterilized seeds in Murashige and Skoog medium [72] and $2 \%$ sucrose at $22^{\circ} \mathrm{C}$ with a $16 \mathrm{~h}$ day length at a light irradiance of $200 \mu \mathrm{mol} \mathrm{m}{ }^{-2} \mathrm{sec}^{-1}$. For agroinfiltration experiments, soil-grown tobacco plants were used.

Arabidopsis thaliana (Col-0) was used for stable transformation and confocal microscopy. For in vitro growth, seeds were surface sterilized for $15 \mathrm{~min}$ in $7 \%$ of bleach with $0.05 \%$ Tween-20, washed with sterile water, incubated at $4^{\circ} \mathrm{C}$ for 3 days and plated in Petri dishes with half strength MS medium (2.4 $\mathrm{g} \mathrm{L}^{-1}$ Murashige and Skoog, $5 \mathrm{~g} \mathrm{~L}^{-1}$ sucrose, $0.5 \mathrm{~g} \mathrm{~L}^{-1}$ Monohydrate 2- ethanesulfonic acid and $10 \%$ agar). Plants were grown at $22^{\circ} \mathrm{C}$ with a photoperiod of $16 \mathrm{~h}$ light and a photon flux of $120 \mu \mathrm{mol} \mathrm{m} \mathrm{sec}^{-1}$.

\section{Subtracted cDNA library construction}

Moss colonies were treated with $20 \mu \mathrm{M}$ ABA during 6, 24 and 48 hours and total RNA was extracted from untreated controls and ABA treated plants. Fifty $\mu \mathrm{g}$ of total RNA extracted from each time point were pooled together to constitute a single ABA treated sample and an untreated control. Two $\mu \mathrm{g}$ of mRNA purified from the RNA samples were used for cDNA synthesis. The Clontech PCR Select-cDNA Subtraction Kit (BD Biosciences Clontech) was employed for suppressive subtractive hybridization, using the samples derived from ABA-treated plants as tester and the controls as driver. The secondary PCR products were purified and inserted into PCR II vector and transformed into Escherichia coli TOP 10 competent cells, using TA cloning kit Dual Promoter from Life Technologies. Approximately 800 clones were selected for insert sequencing.

\section{Phylogenetic analysis}

Translated protein sequences from Arabidopsis and rice sHsp genes were retrieved from Phytozome database, based on previous analysis reported in the literature $[8,65]$. For the identification of sHsps genes in the genome of $P$. patens, all annotated genes in the Phytozome database were screened for the presence of the conserved $\alpha$-crystalline domain, using this sequence as a query for a BlastP search. Sequences were aligned with ClustalW in a MEGA version 5 software $[42,43]$ for subsequent phylogenetic analysis. Construction of phylogenetic trees was done using the Neighbor joining method. Due to the large differences in the sizes of some members of the $P$. patens sHsp protein family, only 17 of the 22 genes from this species are shown in the results represented in Figure 1.

Accession numbers of sHsp genes from rice were: Os16.9 I [Os01g0136100], Os16.91 I [Os01g0136000], Os16.92 I[Os01g0136200], Os16.93I [Os01g0135900], Os17.4A I [Os03g0266900], Os17.4B I[Os03g0267200], Os17.4C I [Os03g0267000], Os17.4D I [Os03g0266300], Os17.6C II[Os02g0217900], Os17.8II [Os01g0184100], Os17.6B III [Os02g0782500], Os18.8 IV [Os07g0517100], Os22.2 V [Os05g0500500], Os17.6 PX [Os06g0253100], Os22.3 ER [Os04g0445100], Os26 CP [Os03g0245800], Os22 MT [Os02g0758000], Os22.4 MT [Os06g0219500], Os16.9C [Os02g0711300], Os17.6A [Os01g0135800], Os18 [Os11g0244200], Os18.2 [Os02g128000], Os21.2 [Os02g0107100]. Accession numbers of sHsp genes from Arabidopsis were: AtHsp17.4I [At3g46230], AtHsp18.1I [At5g59720], AtHsp17.6BI [At2g29500], AtHsp17.6AI [At1g59860], AtHsp17.8I [At1g07400], AtHsp17.6CI [At1g53540], AtHsp18.5VI [At2g19310], AtHsp22.0ER 
[At4g10250], AtHsp15.4IV [At4g21870], AtHsp15.7PX [At5g37670], AtHsp21.7 V [At5g54660], AtHsp17.4III [At1g54050], AtHsp17.6II [At5g12020], AtHsp17.7II [At5g12030], AtHsp14.2 [At5g47600], AtHsp26.5 [At1g52 560], AtHsp21CP [At4g27670], AtHsp23.5MT [At5g51440], AtHsp23.6MT [At4g25200]. Accession numbers from the deduced sHsp proteins of $P$. patens are listed in Table 1.

\section{Construct design for targeted gene disruption of PpHsp16.4 in P. patens}

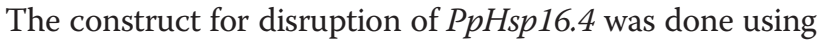
the vector pUBW302 [37], containing the nptII gene driven by the constitutive $35 \mathrm{~S}$ promoter and the 3 'UTR of the ocs gene. A $792 \mathrm{bp}$ genomic fragment from the 5 'region of the PpHsp16.4 gene (bases -711 to 79 bases from the start codon) was cloned upstream from the $35 \mathrm{~S}$ promoter, whereas a 876 bp DNA fragment corresponding to bases 292 to 1168 of the genomic sequence of the gene was inserted downstream of the ocs terminator signal. The genomic sequence for the $5^{\prime}$ insertion was PCR amplified using gene-specific primers containing sequences for restriction enzymes KpnI (forward primer "ccggtacccatccattgatctaac") and HindIII (reverse primer "cacaagcttctggga ctgtggat") to facilitate the subsequent cloning of the fragment. The 3'sequence of the gene was PCR amplified from genomic DNA using the forward primer "tgtggatccggactaccaattgtgact" and reverse primer "acagcggccgcactagcacctcccaa", and cloned in pUBW302 vector using BamHI and NotI restriction enzymes.

\section{Construct design for PpHsp16.4-Citrine in vivo fusion in $P$. patens}

For the knock-in gene fusion construct we used the vector pCTRN-NPTII 2, generated by Makino $\mathrm{H}$. et al. and acquired from the Physcobase clone collection (http:// moss.nibb.ac.jp). A DNA fragment corresponding to bases -25 to 967 (from the start codon) of the genomic sequence of PpHsp16.4, including the entire coding sequence of the gene and lacking the stop codon, was PCR amplified from $P$. patens genomic DNA using the primers "gtggtaccttggtcaacttgagagaa" (forward) and "atcgatatctcc ccccatagtcacctc" (reverse), containing KpnI and EcoRV restriction sites, respectively. This fragment was cloned upstream and in frame with the Citrine gene of the vector pCTRN-NPTII 2. Subsequently, a 1131 bp 3'region of PpHsp16.4 genomic locus, including the 3'UTR of the gene and part of the adjacent genomic sequence (bases 995 to 2099), was amplified by PCR using the primers "acaggatccgggctctctagaaatgac" (forward) and "ttcgcggccgca agctttggtttatg" (reverse), which contained restriction sites for BamHI and NotI, respectively. This fragment was inserted downstream of the nptII selection cassette of the vector in order to direct two events of homologous recombination in the PpHsp16.4 locus.

\section{Generation of $P$. patens transgenic lines}

The generation of moss protoplasts and the subsequent transformation were done as described by Schaefer et al [69]. Briefly, isolated protoplasts (final concentration of $1.6 \times 10^{6}$ per $\mathrm{ml}$ ) were incubated with $30 \mu \mathrm{g}$ of linearized plasmid DNA (digested with KpnI). After polyethylene glycol treatment, protoplasts were incubated for 7 days at $22^{\circ} \mathrm{C}$ on BCDAT medium supplemented with $10 \mathrm{mM}$ $\mathrm{CaCl}_{2}$ and $0.44 \mathrm{M}$ mannitol. Protoplasts were thereafter transferred to BCDAT medium supplemented with $40 \mu \mathrm{g} \mathrm{mL} \mathrm{m}^{-1}$ of G418 and cultured for 10 days. Protoplasts were subsequently allowed to grow for 10 days on BCDAT medium without selection and finally returned to BCDAT medium containing $40 \mu \mathrm{g} \mathrm{mL} \mathrm{m}^{-1}$ of G418. Plants showing growth after two weeks on selection medium were analyzed for the correct incorporation of the transgene on the PpHsp16.4 locus.

\section{Molecular characterization of knockout mutants}

The incorporation of the gene targeting construct in the PpHsp16.4 locus was confirmed by PCR amplification of genomic DNA using the following primers: (a) "ataaaaacaaataaatacaaaaacct" or (e) "catccattctacttgttgaaccacct", forward primers for PpHsp16.4a or PpHsp16.4b, respectively, in combination with the reverse primer (c) "ctttc tctgtgttcttgatgcagttag". To identify possible head-to-tail concatemers we used primer (c) together with primer (d) "ctacccgtgatattgctgaagagc". Full lenght genomic sequences were amplified by using primer (a) with primer (b) "tatagatattccttatattcaactcaa" for $P p H s p 16.4 a$, and primer (e) together with (f) "catcttcttgcattattcttgggge" for $\mathrm{PpHsp16.4b}$ gene. To verify the lack of functional PpHsp16.4a and PpHsp16.4b genes due to targeted gene disruption in the $P$. patens mutants, total RNA was isolated from wild-type and mutant genotypes, treated with $50 \mu \mathrm{M}$ ABA for 24 hours. Northern blot analysis were performed as described below in this section, using the full length cDNA sequence of PpHsp16.4 radiolabeled as a probe.

\section{Northern blot}

Total RNA was isolated from control or treated $P$. patens tissues corresponding to 20 to 30 colonies, using standard procedures based on phenol/chloroform extraction followed by $\mathrm{LiCl}$ precipitation. Ten $\mu \mathrm{g}$ of total RNA separated in denaturing formaldehyde agarose gels were transferred to nylon membranes (Hybond XL, Amersham Pharmacia Biotech), according to Sambrook et al [73]. Membranes were prehybridized at $65^{\circ} \mathrm{C}$ in $5 \times$ SSPE, $5 \times$ Denhardt's solution, $0.2 \%$ SDS and $0.5 \mathrm{mg} \mathrm{mL}^{-1}$ denatured salmon sperm DNA. Hybridizations were performed at $65^{\circ} \mathrm{C}$ overnight. The DNA fragments corresponding to full-length cDNA sequences of $P p H s p 16.4$ or $P p D H N A$ [EMBL:AAR13080.1 or Phypa_221321] were labeled with $\left[\alpha^{32} \mathrm{P}\right]-\mathrm{dCTP}$ using the Rediprime II random priming 
labeling system (Amersham Pharmacia Biotech) and used as probe in these studies. Filters were washed twice for $30 \mathrm{~min}$ at $65^{\circ} \mathrm{C}$ with $5 \times$ SSC-0.5\% SDS, and twice using the same conditions with $1 \times$ SSC- $0.5 \%$ SDS, and exposed in autoradiography films. Ethidium bromide staining was used to ensure equal amounts of loading of RNA in the samples.

\section{Southern blot}

Genomic DNA was extracted as described by Dellaporta et al [74] with an additional RNase treatment and phenol extraction using fresh plant material. The genomic DNA was analyzed by digesting $10 \mu \mathrm{g}$ with BamHI and Pst restriction enzymes. Restricted DNA was separated in $1 \%$ agarose gels and transferred into nylon filters (Hybond XL, Amersham Pharmacia Biotech) according to Sambrook et al [73]. Membranes were prehybridized and hybridized as described for the Northern blot analysis. A DNA fragment corresponding to an NcoI restriction fragment consisting on part of the $35 \mathrm{~S}$ promoter and the nptII gene from the selection cassette, was labeled with $\left[\alpha^{32} \mathrm{P}\right]-\mathrm{dCTP}$ using the Rediprime II random priming labeling system (Amersham Pharmacia Biotech) and used as probe in these studies.

\section{Molecular characterization of $P$. patens PpHsp16.4-Citrine knock-in lines}

The incorporation of the gene targeting construct PpHsp16.4-Citrine in the PpHsp16.4 locus was confirmed by PCR amplification of genomic DNA using the following primers: (g) "ccggtacccatccattgatctaac" and (h) "cgcctcgccggacacgctgaact", specific for a genomic region upstream the targeting construct and the Citrine gene, respectively. To verify the correct expression of PpHsp16.4:Citrine in P. patens knock-in lines, Western blots were performed with protein samples extracted from transgenic lines untreated controls, or treated with $50 \mu \mathrm{M}$ $\mathrm{ABA}$, incubated at $37^{\circ} \mathrm{C}$ or in $300 \mathrm{mM} \mathrm{NaCl}$ or $500 \mathrm{mM}$ mannitol containing plates for 24 hours. Furthermore, plants were incubated for $48 \mathrm{~h}$, at $37^{\circ} \mathrm{C}$ and thereafter transferred to optimal growth conditions for 6 hours, to determine the fusion protein levels during stress recovery. Western blot analysis were performed as described in Saavedra et al [37]. Briefly, soluble plant proteins were extracted in $50 \mathrm{mM}$ Tris- $\mathrm{HCl} \mathrm{pH} \mathrm{7.2,} 250 \mathrm{mM}$ sucrose, 5 mM EDTA pH 8.0, $10 \mathrm{mM} \beta$-mercaptoethanol, $10 \mathrm{mM}$ $\mathrm{MgCl}_{2}, 1 \mathrm{mM} \mathrm{CaCl}$ and $1 \mathrm{mM}$ PMSF. Ten $\mu \mathrm{g}$ of soluble proteins were separated in $10 \%$ polyacrylamide gels and electroblotted onto nitrocellulose membranes (HybondECL, Amersham, GE Healthcare). Blots were incubated with $0.5 \%$ Ponceau red for 10 minutes and washed with distilled water. Ponceau staining of ribulose-1,5-bis-phosphate carboxylase/oxygenase (Rubisco) large subunit served as loading controls. Membranes were blocked in Tris- buffered saline (TBS, $20 \mathrm{mM}$ Tris- $\mathrm{HCl}, 150 \mathrm{mM} \mathrm{NaCl}$ $\mathrm{pH} 7.4$ ) containing $5 \%$ (weight in volume, w/v) skimmed milk powder and $0.2 \%$ Tween-20 for one hour at room temperature. The primary antibodies used in this study were the commercial anti-GFP antibody produced in rabbit (Sigma Aldrich), $1 \mathrm{mg} / \mathrm{ml}$ stock, diluted 1/4000 in TBS, $0.1 \%$ Tween, or the polyclonal antisera anti-PpDHNA [37], diluted 1/1500. Horseradish peroxidase-labeled goat anti-rabbit antibody (Sigma Aldrich) diluted 1/10000 in TBS-Tween $0.1 \%$ was used as secondary antibody. Protein reactions were visualized in autoradiography films using the ECL detection system.

\section{Construct design for cDNA fusion with GFP}

Full length cDNA of PpHsp16.4, lacking the stop codon, was PCR amplified from total ARN samples extracted from $P$. patens treated with $50 \mu \mathrm{M}$ ABA for 24 hours, using the following primers: forward "gtggatccttggtcaacttgagag" and reverse "atatctcgagtgctttcccccatagtcac". The resulting PCR fragment was cloned using BamHI and $X$ hoI restriction enzymes into the pENTR2B entry vector (Gateway, Invitrogen). This construct was thereafter used for LR-mediated recombination of PpHsp16.4 cDNA sequence into the pK7FWG2 destination binary vector [75], containing the GFP coding sequence under the regulation of the $35 \mathrm{~S}$ promoter. The PpHsp16.4 cDNA sequence was fused in frame to the 5' end of GFP, resulting in the chimeric gene 35S:PpHsp16.4-GFP. The resulting construct was introduced in Agrobacterium tumefaciens strain pGV3101/pMP90 [76] by electroporation.

\section{Arabidopsis transformation and molecular characterization of transgenic lines}

The 35S:PpHsp16.4-GFP construct was introduced into Arabidopsis (Col-0) by Agrobacterium-mediated floral dip transformation method [77]. T1 seeds of infiltrated plants were collected and selected by germination on agar-solidified half strength MS medium containing 0.5\% sucrose and $50 \mathrm{mg} \mathrm{L}^{-1}$ kanamycin. Subsequently, $50 \mathrm{ka}-$ namycin resistant seedlings were transferred into soil to produce seeds. Homozygous transgenic lines were produced from kanamycin resistant T2 seedlings and used for further analysis. Ten individual resistant lines of each construct were selected for detail molecular analysis. Expression of the transgenes and presence of the PpHsp16. 4-GFP fusion protein was tested in 10 independent lines by RT-PCR and western blot analysis.

\section{Phenotypic characterization of PpHsp16.4 knockout mutants}

For osmotic stress, wild type and mutant genotypes from $P$. patens were grown for 3 weeks on cellophane overlaid BCDAT medium and thereafter transferred to $900 \mathrm{mM}$ mannitol supplemented plates for 10 days. Plant survival 
was tested by transferring stressed colonies back to standard medium and monitored up to 17 days of recovery. For salt stress, a similar procedure was employed, but using $500 \mathrm{mM} \mathrm{NaCl}$ as a stressor. Heat stress was performed similarly, but incubating the plates at $37^{\circ} \mathrm{C}$ for 7 days.

Chlorophyll content, fresh weight and dry weight of plants were determined in three independent experiments using 3 plates containing 5 colonies per genotype per treatment and per time point. Dry weight was measured after incubation of individual plant colonies on cellophane discs for $16 \mathrm{~h}$ at $80^{\circ} \mathrm{C}$. For the determination of chlorophyll content, each plant was ground up in a mortar containing $5 \mathrm{ml}$ of $80 \%$ (volume in volume, v/v) acetone and the homogenized plant material was filtered to remove cell debris. Total chlorophyll was calculated as chlorophyll $a$ +chlorophyll $b$ (mg g $\mathrm{g}^{-1}$ fresh weight) using the following formula: $\mathrm{Chl} a \mathrm{mg} \mathrm{g}^{-1}=[(12.7 \times$ Abs663) - $(2.6 \times$ Abs645) $] \times$ ml acetone $\mathrm{mg}^{-1}$ fresh tissue; $\mathrm{Chl} b \mathrm{mg} \mathrm{g}^{-1}=[(22.9 \times \mathrm{Abs645})-(4.68 \times \mathrm{Abs663})] \times \mathrm{ml}$ acetone $\mathrm{mg}^{-1}$ fresh tissue.

\section{Subcellular localization of PpHsp16.4-GFP in tobacco and Arabidopsis}

For transient expression experiments, tobacco leaf protoplasts were obtained from in vitro grown plants and electroporated with the construct 35S:PpHsp16.4-GFP or 35S:GFP, following the procedure described in [78]. Protoplasts were analyzed 24 hours after transfection by confocal laser microscopy. For agroinfiltration experiments, soil-grown tobacco plants were infiltrated with Agrobacterium tumefaciens cultures containing the construct 35S: PpHsp16.4-GFP as described [79]. Two days after infiltration, tobacco leaf squares were mounted in tap water and analyzed by confocal laser microscopy for GFP fluorescence.

Stable Arabidopsis transgenic lines, overexpressing PpHsp16.4-GFP were grown in vitro for 6 days and root and hypocotyl sections were mounted in tap water and analyzed by confocal microscopy. Confocal imaging was performed using a confocal laser scanning microscope Leica TCS-SP5, with an excitation of $488 \mathrm{~nm}$ for GFP.

\section{Spatial and subcellular localization of $\mathrm{PpHsp}$ 16.4:Citrine proteins in transgenic knock-in $P$. patens}

Twenty 20 days old colonies of transgenic P. patens lines, expressing PpHsp16.4-Citrine, under the control of the native promoter of the target gene, were used to examine the expression and localization pattern of the fusion protein in protonema filaments and in the leafy gametophyte. Stress treatments were done for 24 hours by transferring plants to $500 \mathrm{mM}$ mannitol supplemented media for osmotic stress, or by incubating them at $37^{\circ} \mathrm{C}$. Protoplasts from $P$. patens transgenic knock-in lines were obtained as described above for the generation of $P$. patens transgenic lines. In vivo fluorescence microscopic observations were made using confocal laser scanning microscope Leica TCS-SP5, using $488 \mathrm{~nm}$ for the fluorescence excitation of Citrine.

\section{Additional files}

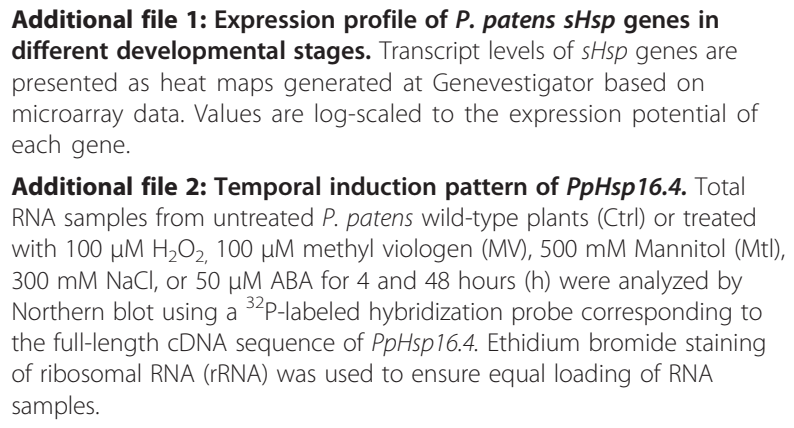

Additional file 2: Temporal induction pattern of PpHsp16.4. Total RNA samples from untreated $P$. patens wild-type plants (Ctrl) or treated with $100 \mu \mathrm{M} \mathrm{H}_{2} \mathrm{O}_{2}, 100 \mu \mathrm{M}$ methyl viologen (MV), $500 \mathrm{mM}$ Mannitol (Mtl), $300 \mathrm{mM} \mathrm{NaCl}$, or $50 \mu \mathrm{M} \mathrm{ABA}$ for 4 and 48 hours (h) were analyzed by Northern blot using a ${ }^{32}$ P-labeled hybridization probe corresponding to the full-length cDNA sequence of PpHsp16.4. Ethidium bromide staining of ribosomal RNA (rRNA) was used to ensure equal loading of RNA samples.

\section{Competing interest}

The authors declare no competing interests.

\section{Authors' contribution}

CR conducted most experiments. AC participated in P. patens transformation and performed phylogenetical analysis. VC generated the subtracted library. LSZ contributed in the generation of Arabidopsis transgenic lines and the subcellular localization studies and revised the manuscript. SV designed and supervised the study, contributed to the analysis of the data and wrote the manuscript. All authors read and approved the final manuscript.

\section{Acknowledgements}

This work was supported by ICGEB-TWAS Plant Biotechnology Program (ICGEB CRP.PB/URU06-01), ANII Fondo Clemente Estable 2007 FCE 534, CSIC Grupos I + D 2010-Borsani, Programa de Desarrollo de Ciencias Básicas (PEDECIBA) and Programa de Posgrado de la CSIC-Udelar. We wish to thank Prof. Ralph S. Quatrano for kindly providing the abi3 line and Prof. Jürgen Denecke for his help with protein localization analysis. We thank Juan Pablo Gallino for his help in the statistical analysis.

\section{Author details}

${ }^{1}$ Laboratorio de Biología Molecular Vegetal, Facultad de Ciencias, Universidad de la República, Iguá 4225, CP 11400 Montevideo, Uruguay. ${ }^{2}$ Institute of Plant Biology, Biological Research Center, Temésvari krt. 62, 6726 Szeged, Hungary. ${ }^{3}$ Current address: Whitehead Institute for Biomedical Research, 9 Cambridge Center, Cambridge, MA 02142, USA.

Received: 29 July 2013 Accepted: 28 October 2013 Published: 5 November 2013

\section{References}

1. Chinnusamy V, Schumaker K, Zhu JK: Molecular genetic perspectives on cross-talk and specificity in abiotic stress signalling in plants. J Exp Bot 2004, 55:225-236.

2. Oliver MJ, Velten J, Mishler BD: Desiccation tolerance in bryophytes: a reflection of the primitive strategy for plant survival in dehydrating habitats? Integr Comp Biol 2005, 45:788-799.

3. Shinozaki K, Yamaguchi-Shinozaki K: Molecular responses to dehydration and low temperature: differences and cross-talk between two stress signaling pathways. Curr Opin Plant Biol 2000, 3:217-223.

4. Bray EA: Plant responses to water deficit. Trends Plant Sci 1997, 2:48-54.

5. Zhu JK: Salt and drought stress signal transduction in plants. Annu Rev Plant Biol 2002, 53:247-273

6. Bouchabke-Coussa O, Quashie M-L, Seoane-Redondo J, Fortabat M-N, Gery C, Yu A, Linderme D, Trouverie J, Granier F, Teoule E, Durand-Tardif M: 
ESKIMO1 is a key gene involved in water economy as well as cold acclimation and salt tolerance. BMC Plant Biol 2008, 8:125.

7. Krasensky J, Jonak C: Drought, salt, and temperature stress-induced metabolic rearrangements and regulatory networks. J Exp Bot 2012, 63:1593-1608

8. Scharf KD, Siddique M, Vierling E: The expanding family of Arabidopsis thaliana small heat stress proteins and a new family of proteins containing alpha-crystallin domains (Acd proteins). Cell Stress Chaperon 2001, 6:225-237.

9. Forreiter C, Kirschner M, Nover L: Stable transformation of an Arabidopsis cell suspension culture with firefly luciferase providing a cellular system for analysis of chaperone activity in vivo. Plant Cell 1997, 9:2171-2181.

10. Lee GJ, Roseman AM, Saibil HR, Vierling E: A small heat shock protein stably binds heat-denatured model substrates and can maintain a substrate in a folding-competent state. EMBO J 1997, 16:659-671.

11. Heckathorn SA, Downs CA, Sharkey TD, Coleman JS: The small, methionine-rich chloroplast heat-shock protein protects photosystem II electron transport during heat stress. Plant Physiol 1998, 116:439-444.

12. Löw D, Brandle K, Nover L, Forreiter C: Cytosolic heat-stress proteins Hsp17.7 class I and Hsp17.3 class II of tomato act as molecular chaperones in vivo. Planta 2000, 211:575-582

13. de Jong WW, Caspers GJ, Leunissen JA: Genealogy of the alpha-crystallin-small heat-shock protein superfamily. Int J Biol Macromol 1998, 22:151-162.

14. Bondino HG, Valle EM, Ten Have A: Evolution and functional diversification of the small heat shock protein/a-crystallin family in higher plants. Planta 2012, 235:1299-1313.

15. Waters ER: The evolution, function, structure, and expression of the plant sHSPs. J Exp Bot 2013, 64:391-403.

16. Sabehat A, Lurie $S$, Weiss D: Expression of small heat-shock proteins at low temperatures. A possible role in protecting against chilling injuries. Plant Physiol 1998, 117:651-658

17. Asada K: Production and action of active oxygen species in photosynthetic tissues. In Causes of photooxidative stress and amelioration of defense systems in plants. Edited by Foyer CH, Mullineaux PM. Florida: CRC Press; 1994:77-104

18. Almoguera C, Coca MA, Jordano J: Tissue-specific expression of sunflower heat shock proteins in response to water stress. Plant J 1993, 4:947-958.

19. Alamillo J, Almoguera C, Bartels D, Jordano J: Constitutive expression of small heat shock proteins in vegetative tissues of the resurrection plant Craterostigma plantagineum. Plant Mol Biol 1995, 29:1093-1099.

20. Harndahl U, Hall RB, Osteryoung KW, Vierling E, Bornman JF, Sundby C: The chloroplast small heat shock protein undergoes oxidation-dependent conformational changes and may protect plants from oxidative stress. Cell Stress Chaperon 1999, 4:129-138.

21. Hamilton EW, Heckathorn SA: Mitochondrial adaptations to $\mathrm{NaCl}$. Complex I is protected by anti-oxidants and small heat shock proteins, whereas complex II is protected by proline and betaine. Plant Physiol 2001, 126:1266-1274

22. Sun W, Van Montagu M, Verbruggen N: Small heat shock proteins and stress tolerance in plants. Biochim Biophys Acta 2002, 1577:1-9.

23. Wehmeyer $\mathrm{N}$, Vierling $\mathrm{E}$ : The expression of small heat shock proteins in seeds responds to discrete developmental signals and suggests a general protective role in desiccation tolerance. Plant Physiol 2000, 122:1099-1108.

24. Wu C: Heat shock transcription factors: structure and regulation. Annu Rev Cell Develop Biol 1995, 11:441-469.

25. Schöffl F, Prändl R, Reindl A: Regulation of the heat-shock response. Plant Physiol 1998, 117:1135-1141.

26. Pelham HR: A regulatory upstream promoter element in the Drosophila hsp 70 heat-shock gene. Cell 1982, 30:517-528.

27. von Koskull-Doring P, Scharf K-D, Nover L: The diversity of plant heat stress transcription factors. Trends Plant Sci 2007, 12:452-457.

28. Kotak S, Vierling E, Bäumlein H, Koskull-Döring PV: A novel transcriptional cascade regulating expression of heat stress proteins during seed development of Arabidopsis. Plant Cell 2007, 19:182-195.

29. Ehrnsperger M, Graber S, Gaestel M, Buchner J: Binding of non-native protein to Hsp25 during heat shock creates a reservoir of folding intermediates for reactivation. EMBO J 1997, 16:221-229.

30. Veinger L, Diamant S, Buchner J, Goloubinoff $P$ : The small heat-shock protein $\mathrm{lbpB}$ from Escherichia coli stabilizes stress-denatured proteins for subsequent refolding by a multichaperone network. J Biol Chem 1998, 273:11032-11037.
31. Lee GJ, Vierling E: A small heat shock protein cooperates with heat shock protein 70 systems to reactivate a heat-denatured protein. Plant Physiol 2000, 122:189-198

32. Reddy GB, Das KP, Petrash JM, Surewicz WK: Temperature-dependent chaperone activity and structural properties of human alphaA- and alphaB-crystallins. J Bio/ Chem 2000, 275:4565-4570.

33. Nakamoto $H$, Vigh $L$ : The small heat shock proteins and their clients. Cell Mol Life Sci 2007, 64:294-306.

34. Waters ER, Lee GJ, Vierling E: Evolution, structure and function of the small heat shock proteins in plants. J Exp Bot 1996, 47:325-338.

35. Mogk A, Schlieker C, Friedrich KL, Schonfeld HJ, Vierling E, Bukau B: Refolding of substrates bound to small Hsps relies on a disaggregation reaction mediated most efficiently by ClpB/DnaK. J Bioll Chem 2003, 278:31033-31042.

36. Schaefer DG, Zryd JP: Efficient gene targeting in the moss Physcomitrella patens. Plant J 1997, 11:1195-1206.

37. Saavedra L, Svensson J, Carballo V, Izmendi D, Welin B, Vidal S: A dehydrin gene in Physcomitrella patens is required for salt and osmotic stress tolerance. Plant J 2006, 45:237-249.

38. Charron AJ, Quatrano RS: Between a rock and a dry place: the water-stressed moss. Mol Plant 2009, 2:478-486.

39. Frank W, Ratnadewi D, Reski R: Physcomitrella patens is highly tolerant against drought, salt and osmotic stress. Planta 2005, 220:384-394.

40. Wang XQ, Yang PF, Liu Z, Liu WZ, Hu Y, Chen H, Kuang TY, Pei ZM, Shen $\mathrm{SH}, \mathrm{He}$ YK: Exploring the mechanism of Physcomitrella patens desiccation tolerance through a proteomic strategy. Plant Physiol 2009, 149:1739-1750.

41. Goodstein DM, Shu S, Howson R, Neupane R, Hayes RD, Fazo J, Mitros T, Dirks W. Hellsten U, Putnam N, et al: Phytozome: a comparative platform for green plant genomics. Nucleic Acids Res 2012, 40:D1178-D1186.

42. Thompson JD, Gibson TJ, Plewniak F, Jeanmougin F, Higgins DG: The CLUSTAL_X windows interface: flexible strategies for multiple sequence alignment aided by quality analysis tools. Nucleic Acids Res 1997 25:4876-4882.

43. Tamura K, Peterson D, Peterson N, Stecher G, Nei M, Kumar S: MEGA5: molecular evolutionary genetics analysis using maximum likelihood, evolutionary distance, and maximum parsimony methods. Mol Biol Evol 2011, 28:2731-2739.

44. Zimmermann P, Laule O, Schmitz J, Hruz T, Bleuler S, Gruissem W: Genevestigator transcriptome meta-analysis and biomarker search using rice and barley gene expression databases. Mol Plant 2008, 1:851-857.

45. Ruibal C, Salomó Pérez I, Carballo V, Castro A, Bentancor M, Borsani O, Szabados L, Vidal S: Differential contribution of individual dehydrin genes from Physcomitrella patens to salt and osmotic stress tolerance. Plant SCi 2012, 190:89-102

46. Khandelwal A, Cho SH, Marella H, Sakata Y, Perroud PF, Pan A, Quatrano RS: Role of $A B A$ and $A B I 3$ in desiccation tolerance. Science 2010, 327:546.

47. Heikal AA, Hess ST, Baird GS, Tsien RY, Webb WW: Molecular spectroscopy and dynamics of intrinsically fluorescent proteins: coral red (dsRed) and yellow (Citrine). Proc Natl Acad Sci USA 2000, 97:11996-12001.

48. Kamisugi Y, Schlink K, Rensing SA, Schween G, von Stackelberg M, Cuming AC, Reski R, Cove DJ: The mechanism of gene targeting in Physcomitrella patens: homologous recombination, concatenation and multiple integration. Nucleic Acids Res 2006, 34:6205-6214.

49. Timperio AM, Egidi MG, Zolla L: Proteomics applied on plant abiotic stresses: role of heat shock proteins (HSP). J proteomics 2008, 71:391-411

50. Swindell W, Huebner M, Weber A: Transcriptional profiling of Arabidopsis heat shock proteins and transcription factors reveals extensive overlap between heat and non-heat stress response pathways. BMC Genomics 2007, 8:125.

51. Siddique M, Gernhard S, von Koskull-Doring P, Vierling E, Scharf K-D: The plant sHSP superfamily: five new members in Arabidopsis thaliana with unexpected properties. Cell Stress Chaperon 2008, 1:183-197.

52. Waters E, Aevermann B, Sanders-Reed Z: Comparative analysis of the small heat shock proteins in three angiosperm genomes identifies new subfamilies and reveals diverse evolutionary patterns. Cell Stress Chaperon 2008 13:127-142.

53. Scarpeci TE, Zanor MI, Carrillo N, Mueller-Roeber B, Valle EM: Generation of superoxide anion in chloroplasts of Arabidopsis thaliana during active photosynthesis: a focus on rapidly induced genes. Plant Mol Biol 2008 66:361-378. 
54. Mittler R, Vanderauwera S, Gollery M, Van Breusegem F: Reactive oxygen gene network of plants. Trends Plant Sci 2004, 9:490-498.

55. Miller G, Mittler R: Could heat shock transcription factors function as hydrogen peroxide sensors in plants? Ann Bot 2006, 98:279-288.

56. Neta-Sharir I, Isaacson T, Lurie S, Weiss D: Dual role for tomato heat shock protein 21: protecting photosystem II from oxidative stress and promoting color changes during fruit maturation. Plant Cell 2005, 17:1829-1838.

57. Banzet N, Richaud C, Deveaux Y, Kazmaier M, Gagnon J, Triantaphylides C: Accumulation of small heat shock proteins, including mitochondrial HSP22, induced by oxidative stress and adaptive response in tomato cells. Plant J 1998, 13:519-527.

58. Larkindale J, Huang B: Thermotolerance and antioxidant systems in Agrostis stolonifera: involvement of salicylic acid, abscisic acid, calcium, hydrogen peroxide, and ethylene. J Plant Physiol 2004, 161:405-413.

59. Larkindale J, Hall JD, Knight MR, Vierling E: Heat stress phenotypes of Arabidopsis mutants implicate multiple signaling pathways in the acquisition of thermotolerance. Plant Physiol 2005, 138:882-897.

60. Clarke SM, Mur LAJ, Wood JE, Scott IM: Salicylic acid dependent signaling promotes basal thermotolerance but is not essential for acquired thermotolerance in Arabidopsis thaliana. Plant J 2004, 38:432-447.

61. Chang P-FL JT-L, Huang W-K, Chen Y, Chang H-M, Wang C-W: Induction of a cDNA clone from rice encoding a class II small heat shock protein by heat stress, mechanical injury, and salicylic acid. Plant Sci 2007, 172:64-75.

62. Saidi Y, Domini M, Choy F, Zryd JP, Schwitzguebel JP, Goloubinoff P: Activation of the heat shock response in plants by chlorophenols: transgenic Physcomitrella patens as a sensitive biosensor for organic pollutants. Plant Cell Environ 2007, 30:753-763.

63. Liu H-T, Liu Y-Y, Pan Q-H, Yang H-R, Zhan J-C, Huang W-D: Novel interrelationship between salicylic acid, abscisic acid, and PIP2-specific phospholipase $\mathrm{C}$ in heat acclimation-induced thermotolerance in pea leaves. J Exp Bot 2006, 57:3337-3347.

64. Kotak S, Larkindale J, Lee U, von Koskull-Doring P, Vierling E, Scharf K-D: Complexity of the heat stress response in plants. Curr Opin Plant Biol 2007, 10:310-316.

65. Sarkar N, Kim Y-K, Grover A: Rice sHsp genes: genomic organization and expression profiling under stress and development. BMC Genomics 2009, 10:393.

66. Powles SB: Photoinhibition of photosynthesis induced by visible light. Annu Rev Plant Physiol 1984, 35:15-44.

67. Kim DH, Xu Z-Y, Na YJ, Yoo Y-J, Lee J, Sohn E-J, Hwang I: Small heat shock protein Hsp17.8 functions as an AKR2A cofactor in the targeting of chloroplast outer membrane proteins in Arabidopsis. Plant Physiol 2011, 157:132-146.

68. Baldwin AJ, Lioe $H$, Robinson CV, Kay LE, Benesch JL: alphaB-crystallin polydispersity is a consequence of unbiased quaternary dynamics. J Mol Biol 2011, 413:297-309.

69. Schaefer D, Zryd JP, Knight CD, Cove DJ: Stable transformation of the moss Physcomitrella patens. Mol Gen Genet 1991, 226:418-424.

70. Ashton NW, Cove DJ: The isolation and preliminary characterisation of auxotrophic and analogue resistant mutants of the moss, Physcomitrella patens. Molec Gen Genet 1977, 154:87-95.

71. Maliga PBSZ, Marton L: Streptomycin resistant plants from callus culture of haploid tobacco. Nature 1973, 244:29-30.

72. Murashige R, Skoog F: A revised medium for rapid growth and bioassays with tobacco tissue cultures. Physiol Plant 1962, 15:473-497.

73. Sambrook J, Fritsch EF, Maniatis TA: Molecular Cloning: A Laboratory Manual. 2nd edition. Cold Spring Harbor NY: Cold Spring Harbor Laboratory Press; 1989.

74. Dellaporta S, Wood J, Hicks J: A plant DNA minipreparation: Version II. Plant Mol Biol Rep 1983, 1:19-21.

75. Karimi M, Inze D, Depicker A: GATEWAY vectors for Agrobacterium-mediated plant transformation. Trends Plant Sci 2002, 7:193-195.

76. Koncz C, Schell J: The promoter of TL-DNA gene 5 controls the tissue-specific expression of chimaeric genes carried by a novel type of Agrobacterium binary vector. Molec Gen Genet 1986, 204:383-396.

77. Clough SJ, Bent AF: Floral dip: a simplified method for Agrobacterium-mediated transformation of Arabidopsis thaliana. Plant J 1998, 16:735-743.
78. Foresti O, Da Silva LL, Denecke J: Overexpression of the Arabidopsis syntaxin PEP12/SYP21 inhibits transport from the prevacuolar compartment to the lytic vacuole in vivo. Plant Cell 2006, 18:2275-2293.

79. Neuhaus J-M, Boevink P: The green fluorescent protein (GFP) as a reporter in plant cells. In Plant Cell Biology. Edited by Hawes C, Satiat-Jeunemaitre B. Oxford, UK: Oxford University Press; 2001:127-142.

doi:10.1186/1471-2229-13-174

Cite this article as: Ruibal et al:: Recovery from heat, salt and osmotic stress in Physcomitrella patens requires a functional small heat shock protein PpHsp16.4. BMC Plant Biology 2013 13:174.

\section{Submit your next manuscript to BioMed Central and take full advantage of:}

- Convenient online submission

- Thorough peer review

- No space constraints or color figure charges

- Immediate publication on acceptance

- Inclusion in PubMed, CAS, Scopus and Google Scholar

- Research which is freely available for redistribution 